Universidad de Lima

Facultad de Ciencias Empresariales y Económicas

Carrera de Economía

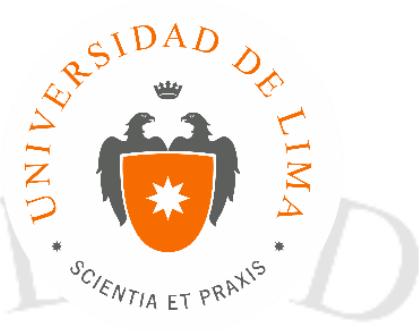

\title{
EMISIONES DE EMPRESAS PERUANAS EN \\ EL MERCADO EXTRANJERO Y LA \\ LIQUIDEZ DE LA BOLSA PERUANA
}

Trabajo de suficiencia profesional para optar el Título Profesional de Economista

Sustentación de caso

\section{Henry Mauricio Diaz da Silva}

Código 20111767

\section{Asesor \\ Javier Penny Pestana}

Lima - Perú

Diciembre de 2018 


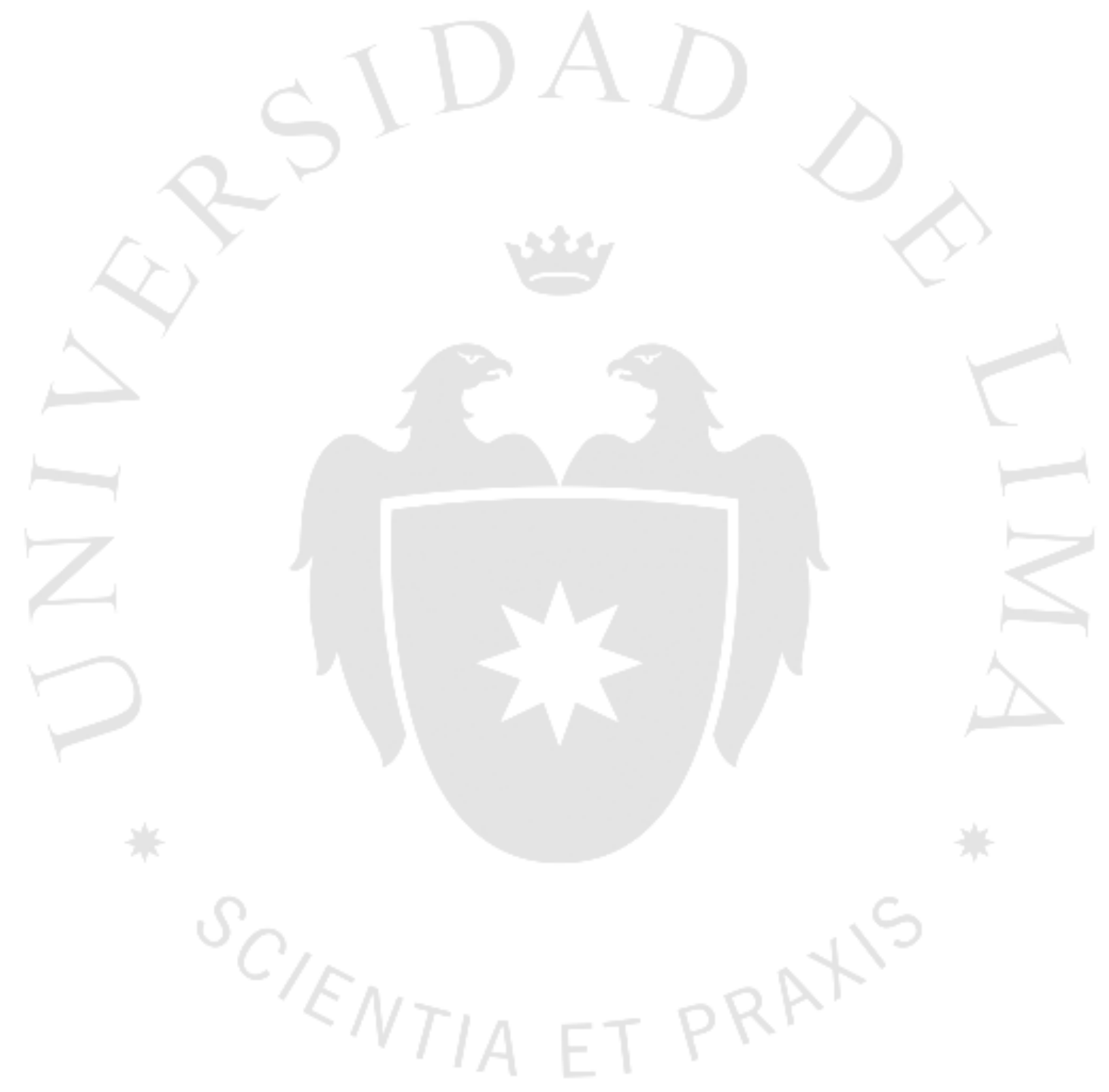




\section{EMISIONES DE EMPRESAS PERUANAS EN \\ EL EXTRANJERO Y LA LIQUIDEZ DE LA BOLSA PERUANA}




\section{TABLA DE CONTENIDO}

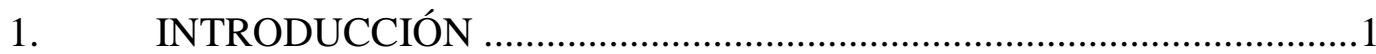

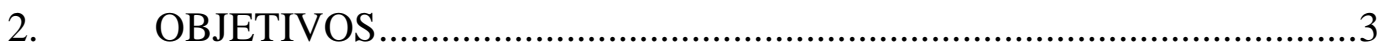

3. PREGUNTAS DE INVESTIGACIÓN .................................................

4. METODOLOGÍA DE RECOLECCIÓN DE LA INFORMACIÓN .........5

5. METODOLOGÍA DE ANÁLISIS DE LA INFORMACIÓN ...................6

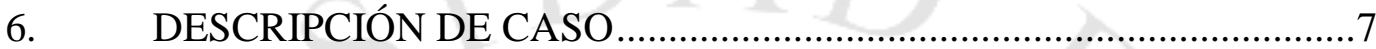

6.1. Panorama macroeconómico del Perú ...........................................................

6.2. El mercado bursátil peruano y su evolución ...............................................13

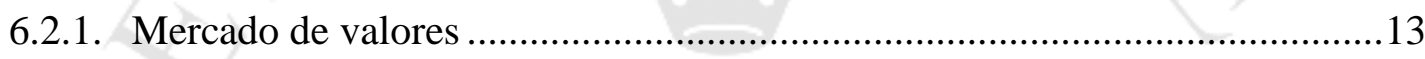

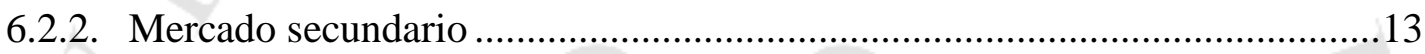

6.2.3. Características de la bolsa de valores..........................................................14

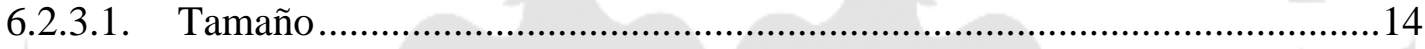

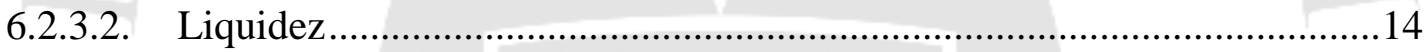

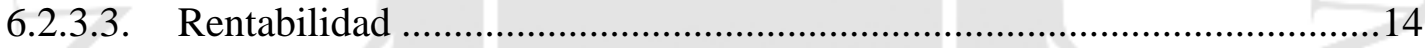

6.2.4. Evolución del mercado bursátil peruano.....................................................15

6.2.5. Evolución y comparación de la BVL con otras bolsas de la región ................17

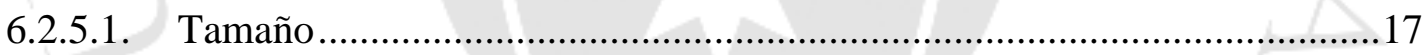

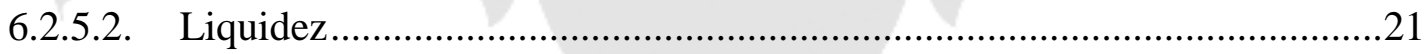

6.3. American Depositary Receipts (ADRs) ….................................................23

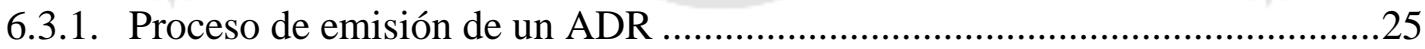

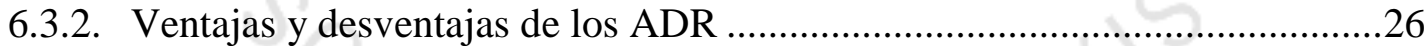

6.4. Principales casos de emisiones de empresas peruanas en el extranjero..........28

7. ANÁLISIS Y DISCUSIÓN DE RESULTADOS ....................................29

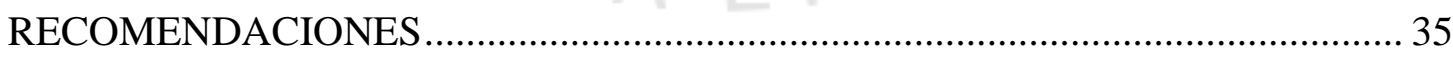

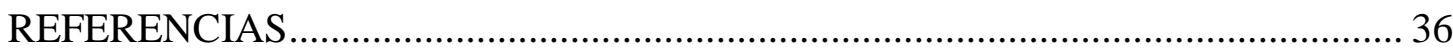

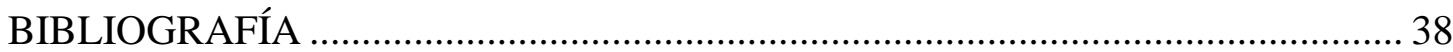




\section{ÍNDICE DE TABLAS}

Tabla 6.1 Principales casos de emisiones de empresas peruanas en el extranjero ........28

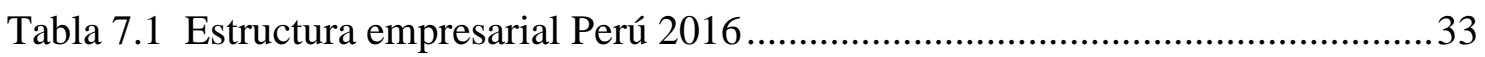




\section{ÍNDICE DE FIGURAS}

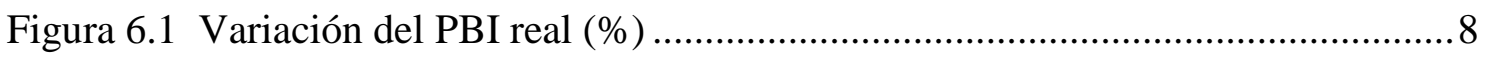

Figura 6.2 Inflación (Var. promedio anual \%) ...........................................................

Figura 6.3 Tasa de desempleo de Lima Metropolitana $(\%)$........................................ 9

Figura 6.4 Pobreza (\% de la población) ....................................................................... 10

Figura 6.5 Pobreza extrema (\% de la población) ......................................................... 11

Figura 6.6 Pobreza monetaria (\% de la población) ..................................................... 11

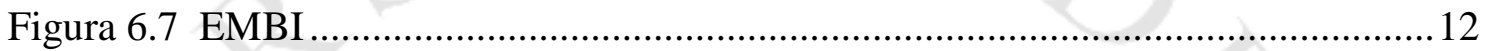

Figura 6.8 Capitalización bursátil (\% del PBI) ....................................................... 16

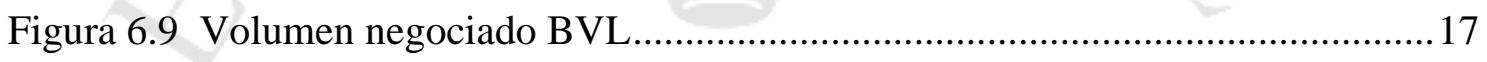

Figura 6.10 BOVESPA vs MILA (market cap en US\$ MM) .................................... 18

Figura 6.11 Composición del MILA (market cap en \%) ............................................. 19

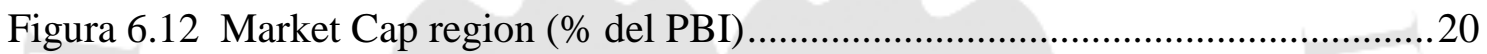

Figura 6.13 Número de compañías listadas (2017) …............................................2

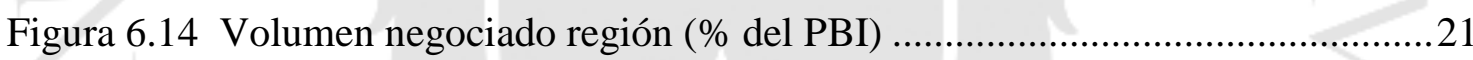

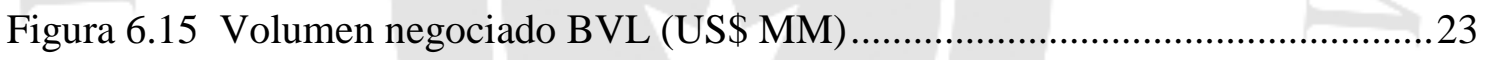

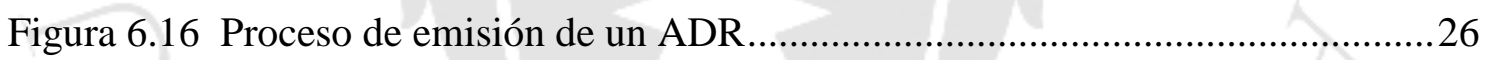

Figura 7.1 Volumen negociado Banco de Crédito del Perú (US\$ MM)......................... 31

Figura 7.2 Volumen negociado Telefónica del Perú (US\$ MM) ................................. 32

Figura 7.3 Volumen negociado Buenaventura ADR (US\$ MM) ................................ 32

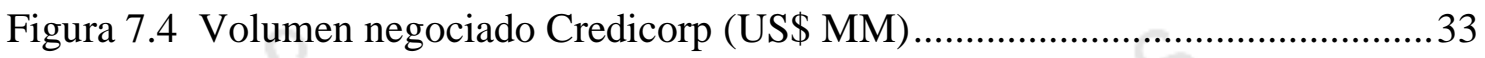




\section{ÍNDICE DE ANEXOS}




\section{INTRODUCCIÓN}

En el 2015, el MSCI, firma internacional que elabora índices bursátiles, anunció que se realizaría una consulta a inversionistas para evaluar la reclasificación del mercado peruano de su actual condición de "mercado emergente" a "mercado fronterizo". Esto debido a que el mínimo de constituyentes del índice MSCI Perú es de tres empresas, las cuales deben cumplir ciertos requerimientos de tamaño, liquidez y acceso al mercado. Ante los problemas de liquidez que enfrentaba la bolsa peruana y la posible reclasificación de las acciones de Southern Copper Corporation (SCC) a los índices de Estados Unidos, lo cual habría dejado con solo dos empresas constituyentes el índice MSCI Perú, el riesgo de la reclasificación a "mercado fronterizo" era significativo.

Una reclasificación a "mercado fronterizo" podría implicar una fuga de capitales de hasta US\$ 1,500 millones en pocos días debido a las restricciones de inversión que tienen los fondos de inversión y las AFPs. Adicionalmente, considerando que uno de los problemas mencionados era la liquidez del mercado, la necesidad de liquidar posiciones en el corto plazo implicaría grandes pérdidas y un posible colapso de los precios de la bolsa peruana. (Arispe, 2015)

Gracias a la rápida acción del gobierno y el sector privado para impulsar reformas de mercado con la finalidad aumentar la liquidez de este y el hecho que las acciones de SCC mantuvieron su clasificación dentro de los índices peruanos, el MSCI decidió mantener la clasificación de "mercado emergente".

Las medidas implementadas por el gobierno y el sector privado como la exoneración temporal de los impuestos a las ganancias de capital para acciones negociadas en la bolsa peruana, las facilidades tributarias e incentivos para los market makers ${ }^{1}$, el préstamo en valores y la venta en corto tienen un impacto inmediato sobre la liquidez de mercado; sin embargo, dejan de lado problemas estructurales de fondo. (Zapatero, s.f.)

${ }^{1}$ Market maker o creador de mercado es un bróker que cotiza tanto el precio de venta como el precio de compra 
El presente estudio tiene como objetivo poner énfasis en el impacto que han generado las emisiones de empresas peruanas en mercados extranjeros en la liquidez de la bolsa peruana. Esto debido a que, al haber grandes beneficios para las empresas emisoras en términos de prestigio y acceso a mejores fuentes de financiamiento, el análisis de las emisiones extranjeras se ha enfocado netamente en sus efectos sobre las empresas emisoras, dejando de lado a los demás agentes que intervienen en la operación y los efectos sobre estos.

La importancia del tema radica en que, dada la estructura empresarial del Perú y las características del mercado bursátil peruano, es relevante explorar y comprender los diferentes enfoques que puedan explicar el porqué, a pesar del buen momento económico que ha experimentado el país, la liquidez del mercado bursátil ha tenido un desempeño inverso, al punto de llevarnos a un posible downgrade ${ }^{2}$.

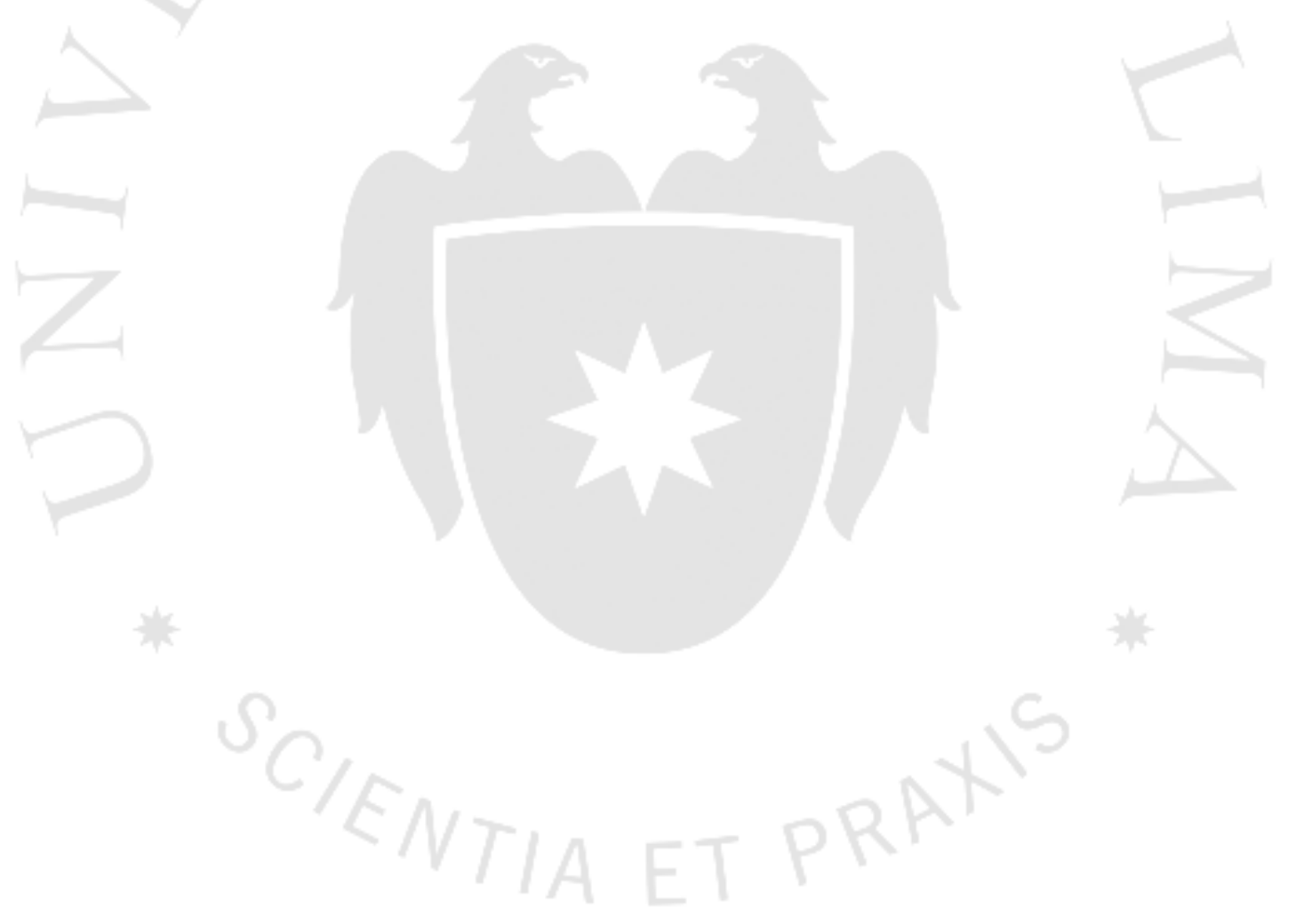

${ }^{2}$ Cambio negativo en una clasificación de riesgo 


\section{OBJETIVOS}

- Comparar los indicadores país con los indicadores bursátiles

- Comparar indicadores del mercado bursátil peruano con otros mercados de la región y demostrar que la liquidez es la variable que muestra mayor atraso.

- Analizar los efectos de las emisiones de empresas peruanas en el extranjero sobre los diferentes agentes que intervienen en la operación

- Determinar que las emisiones de empresas peruanas en mercados extranjeros tienen un efecto negativo en la liquidez del mercado bursátil peruano. 


\section{PREGUNTAS DE INVESTIGACIÓN}

¿Cuáles son los efectos de las emisiones de empresas peruanas en el extranjero sobre los diferentes agentes que intervienen en la operación?

¿Siguen los indicadores bursátiles la misma tendencia que los indicadores macroeconómicos del país?

¿Cómo se encuentra el mercado bursátil peruano respecto a sus principales referentes en la región?

¿Qué llevó a la posible reclasificación a “mercado fronterizo” en el 2015?

¿Cómo afectan las emisiones peruanas en el extranjero a la liquidez del mercado bursátil peruano?

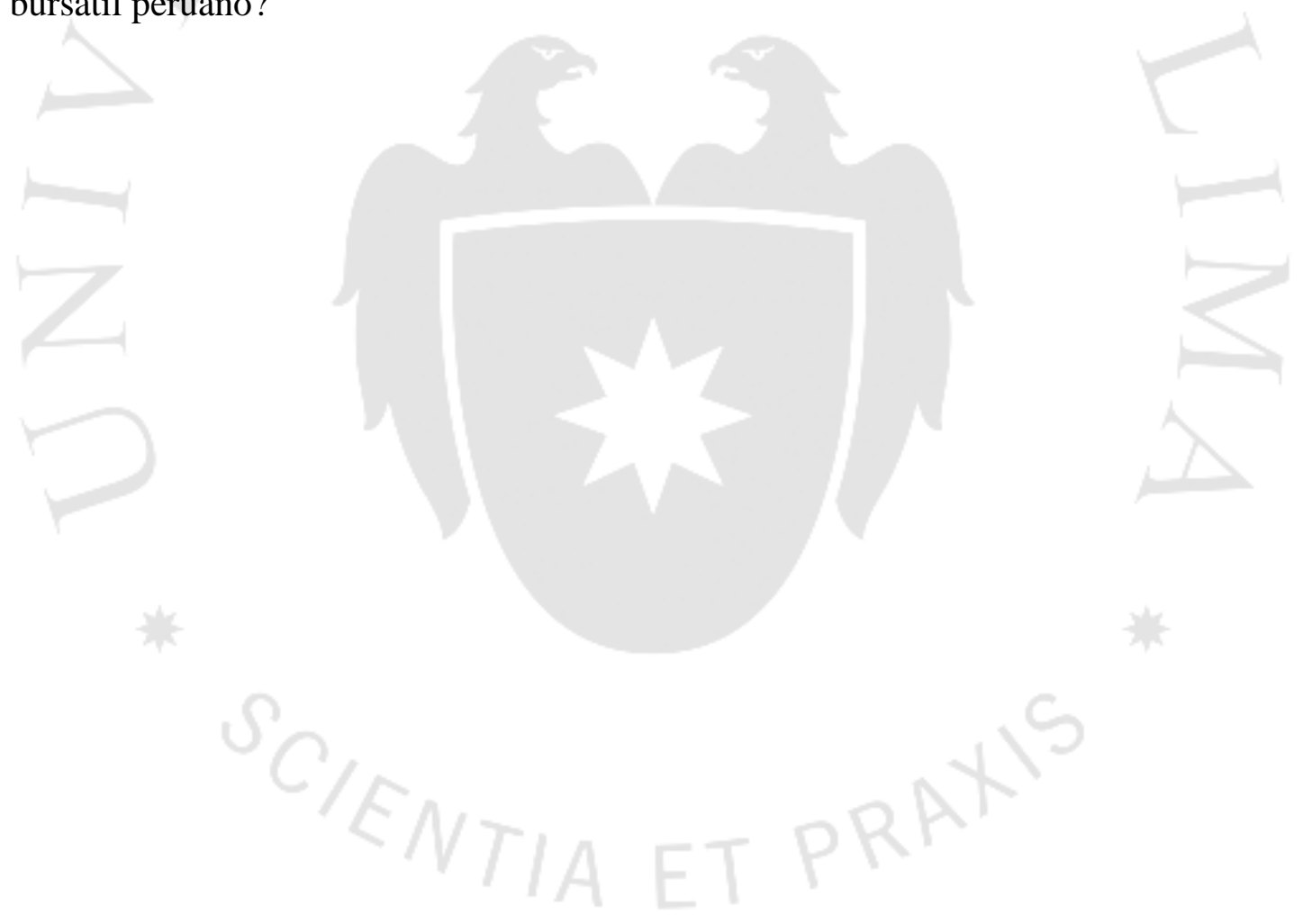




\section{METODOLOGÍA DE RECOLECCIÓN DE LA INFORMACIÓN}

La información sobre la que se basa el caso de estudio proviene de datos secundarios recogidos, principalmente, de datos estadísticos, memorias anuales y reportes a inversionistas por parte de empresas.

Cabe precisar que las fuentes de información de las que se obtienen los datos estadísticos son instituciones gubernamentales oficiales (BCRP, INEI, etc.), instituciones de regulación de mercado (SMV, SBS, SEC, etc.), instituciones directamente relacionadas al mercado bursátil (BVL, WEF, Bloomberg, etc.) así como documentos de transparencia y reporting de las empresas relevantes para el caso de estudio. 


\section{METODOLOGÍA DE ANÁLISIS DE LA INFORMACIÓN}

Tras la recopilación individual de la información sobre indicadores país, se elaboraron gráficos que en conjunto permiten establecer la situación macroeconómica del país en los últimos años.

De igual manera, para la información sobre indicadores bursátiles se elaboraron gráficos comparativos que permiten determinar la situación del Perú respecto a otros mercados de la región LATAM, así como el análisis del nivel de atraso por indicadores.

A partir de la descripción del proceso de emisión de un ADR se procede a analizar los efectos sobre los diferentes agentes que intervienen. Así mismo, mediante la descripción de los principales casos de emisiones extranjeras, se puede determinar el efecto que han tenido sobre la liquidez del mercado bursátil.

Cabe precisar que si bien los indicadores país, los indicadores macroeconómicos y las ventajas de las emisiones extranjeras son tópicos de amplia discusión y análisis en diversos documentos de estudio, el hecho de agruparlos, compararlos y orientar el análisis hacia los efectos de las emisiones extrajeras sobre las bolsas de los países emisores, permiten obtener conclusiones relevantes sobre uno de los problemas más grandes de nuestro mercado bursátil, la liquidez. 


\section{DESCRIPCIÓN DE CASO}

El Perú, desde el año 2000, viene experimentando un gran momento de estabilidad económica. Actualmente, tiene 108 meses de crecimiento ininterrumpido; sin embargo, no todos los sectores productivos del país han reflejado el mismo performance.

Para este caso de estudio es relevante comparar los principales indicadores del país con los del mercado bursátil peruano. Por ello, dividiremos el caso en 4 subtítulos.

En el primero, se muestra el panorama macroeconómico del país mediante sus principales indicadores y su evolución en los últimos 15.

En el segundo, se describe cuáles son las principales características de los mercados bursátiles, qué indicadores se usan para su medición y se mostrará datos estadísticos sobre el mercado bursátil peruano y sus principales referentes regionales.

En el tercero, se explica cuáles son las diferentes modalidades que le permiten a una empresa peruana hacer emisiones en el extranjero.

Por último, en el cuarto subtítulo se describen los principales casos de emisiones en el extranjero de empresas peruanas.

\subsection{Panorama macroeconómico del Perú}

El Perú ha tenido un crecimiento ininterrumpido por los últimos 18 años, consolidándose como una de las economías de más rápido crecimiento en la región, alcanzando un crecimiento promedio de $4.96 \%$ durante este periodo. Esto se debe a un contexto internacional favorable (altos precios de los metales), políticas macroeconómicas prudentes y reformas estructurales en distintos sectores de la economía. Incluso, en el 2009, año en que el efecto de la crisis financiera del 2008 golpeó a la mayoría de los países del mundo, se logró mantener un crecimiento positivo. En el último año, el Perú creció 2.5\%, por debajo de la proyección del MMM de agosto de 2017 (2.8\%) debido al fenómeno del niño y a la crisis política producida por el caso Lava 
Jato. Sin embargo, este crecimiento fue mayor al promedio de América del Sur (0.8\%) y al de América Latina (1.3\%). (CEPAL, 2018)

Figura 6.1

Variación del PBI real (\%)

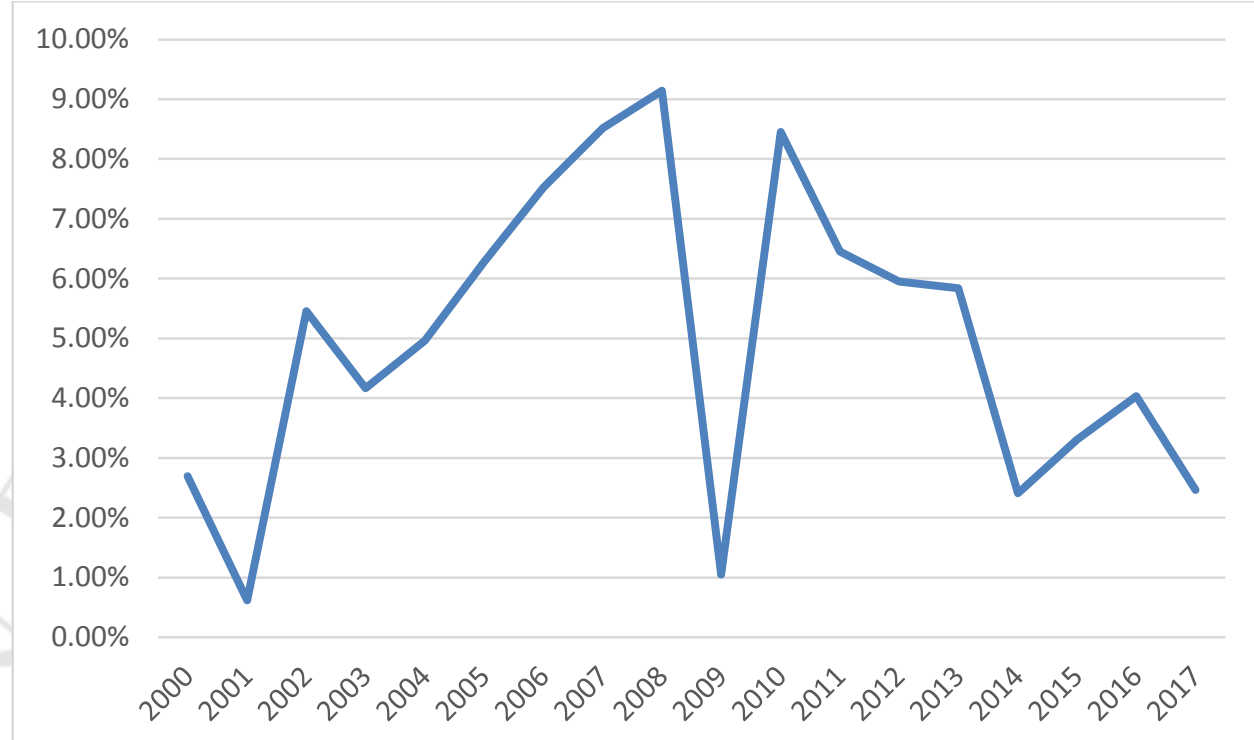

Fuente: Banco Central de Reserva del Perú (s.f.)

Elaboración: Propia

En cuanto a la inflación, el BCRP, en el 2007 redujo la meta de $2.5 \%$ a 2.0\%, con un margen de tolerancia de un punto porcentual hacia arriba o hacia abajo. Meta que se mantiene hasta la actualidad. Esta reducción tuvo como principal argumento fortalecer la desdolarización y el ahorro, así como fortalecer la moneda para permitir el desarrollo del mercado de capitales. De igual manera, se intentó alinear la meta de inflación de Perú a la de sus principales socios comerciales ${ }^{3}$.

${ }^{3}$ La Reserva Federal de Estados Unidos, el Banco Central Europeo, el Banco de Canadá, el Banco de Inglaterra, entre otros, mantiene una inflación meta del $2 \%$ 
Figura 6.2

Inflación (Var. promedio anual \%)

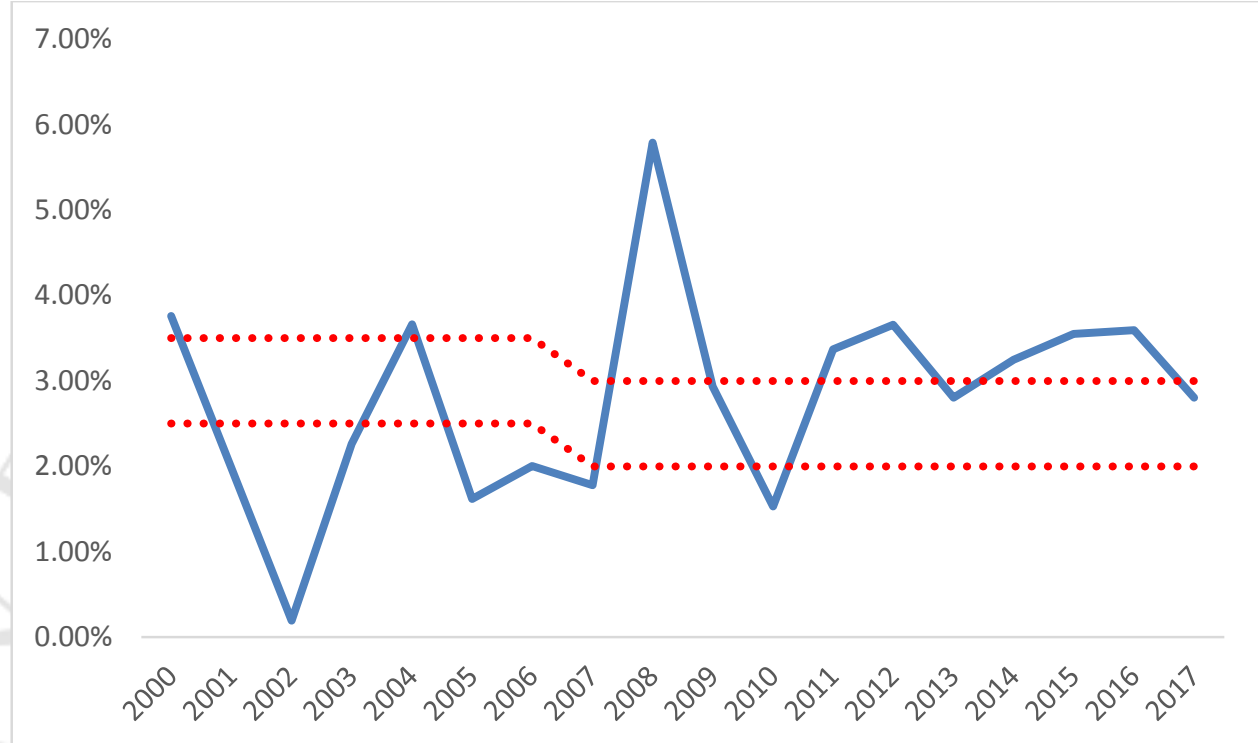

Fuente: Banco Central de Reserva del Perú (s.f.)

Elaboración: Propia

En este gráfico, se puede observar que, con excepción del 2002 y 2008, la inflación se ha mantenido cerca a los márgenes de tolerancia.

Por el lado del desempleo, podemos observar una tendencia decreciente.

Figura 6.3

Tasa de desempleo de Lima Metropolitana (\%)

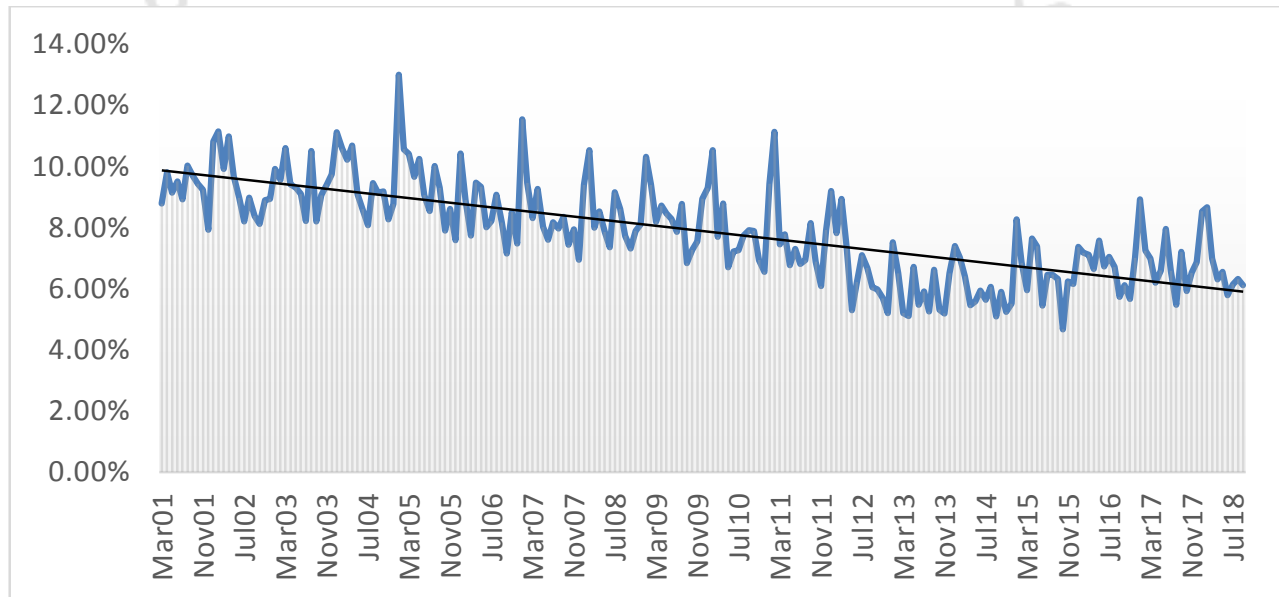

Fuente: Banco Central de Reserva del Perú (s.f.)

Elaboración: Propia 
Por el lado de la pobreza, tanto la pobreza monetaria como la pobreza extrema se han reducido de manera considerable. Entre el 2004 y el 2017 la pobreza monetaria se redujo en más de la mitad, desde un $58.7 \%$ a un $21.7 \%$. De igual manera, la pobreza extrema se redujo de $16.40 \%$ a $3.79 \%$.

Figura 6.4

Pobreza (\% de la población)

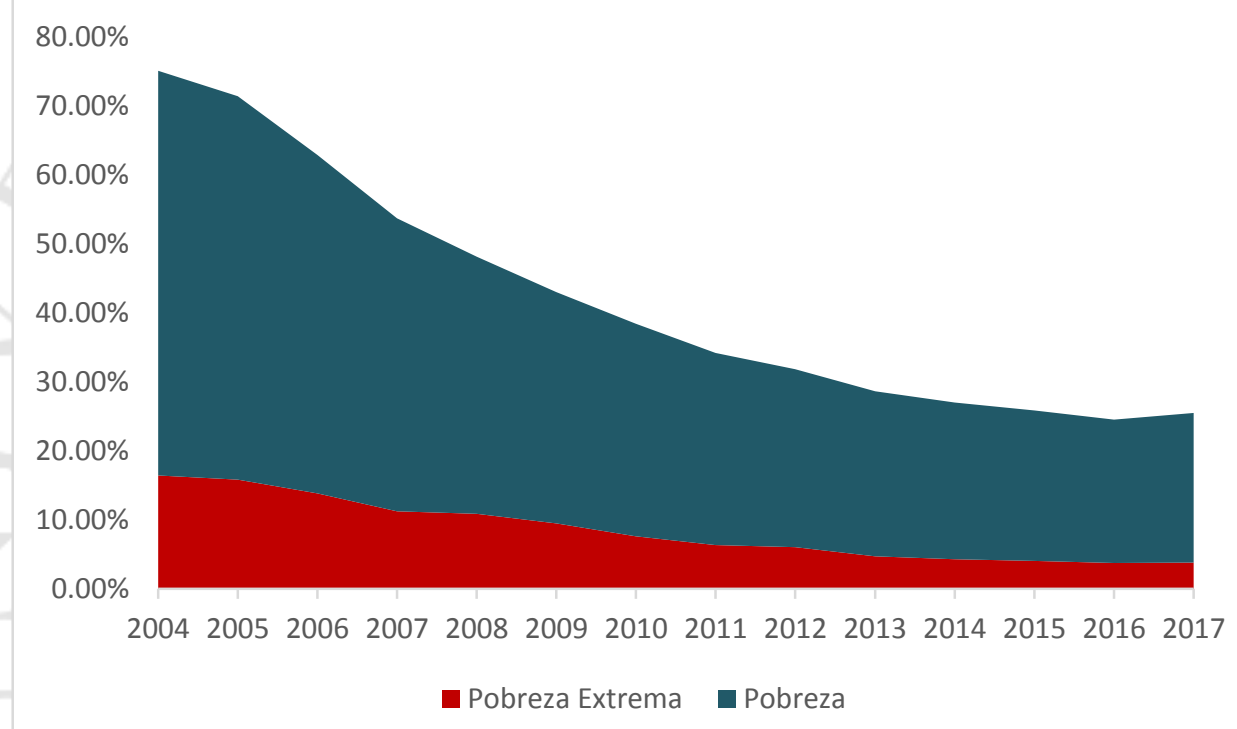

Fuente: Instituto Nacional de Estadística e Informática (s.f.)

Elaboración: Propia

No obstante, cabe resaltar que la pobreza, sea monetaria o extrema, se concentra en la zona rural del país. 
Figura 6.5

Pobreza extrema (\% de la población)

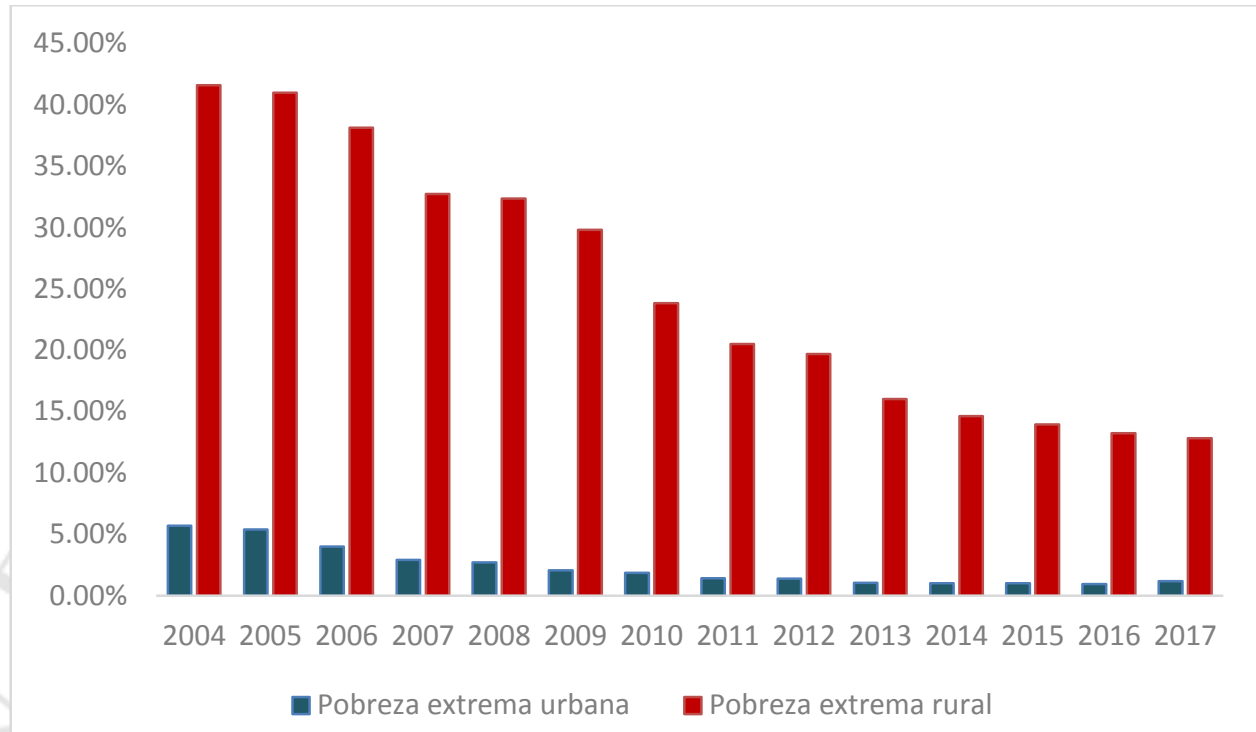

Fuente: Instituto Nacional de Estadística e Informática (s.f.)

Elaboración: Propia

Figura 6.6

Pobreza monetaria (\% de la población)

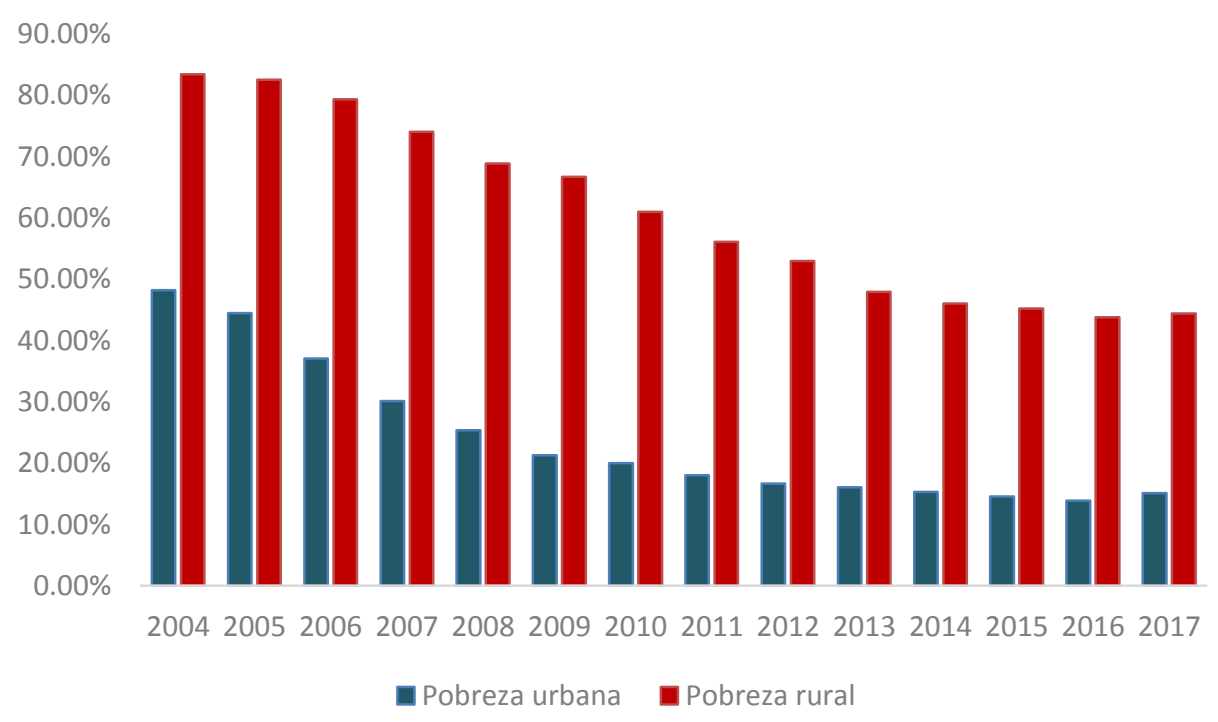

Fuente: Instituto Nacional de Estadística e Informática (s.f.)

Elaboración: Propia 
Se puede observar, que la pobreza extrema rural pasó de ser 7.3 veces (2014) la pobreza extrema urbana a 10.92 veces (2017). Así mismo, la pobreza monetaria rural pasó de ser 1.73 veces (2004) la pobreza monetaria urbana a 2.93 veces (2017).

En general, se observa, a través de los indicadores macroeconómicos, una mejora en el desempeño del país. Al ser esta mejora, en gran parte, producto de un contexto externo favorable, este buen desempeño no es ajeno a la región latinoamericana. Esto se puede apreciar en el indicador $\mathrm{EMBI}^{4}$, el cual mide el riesgo país.

Figura 6.7

EMBI

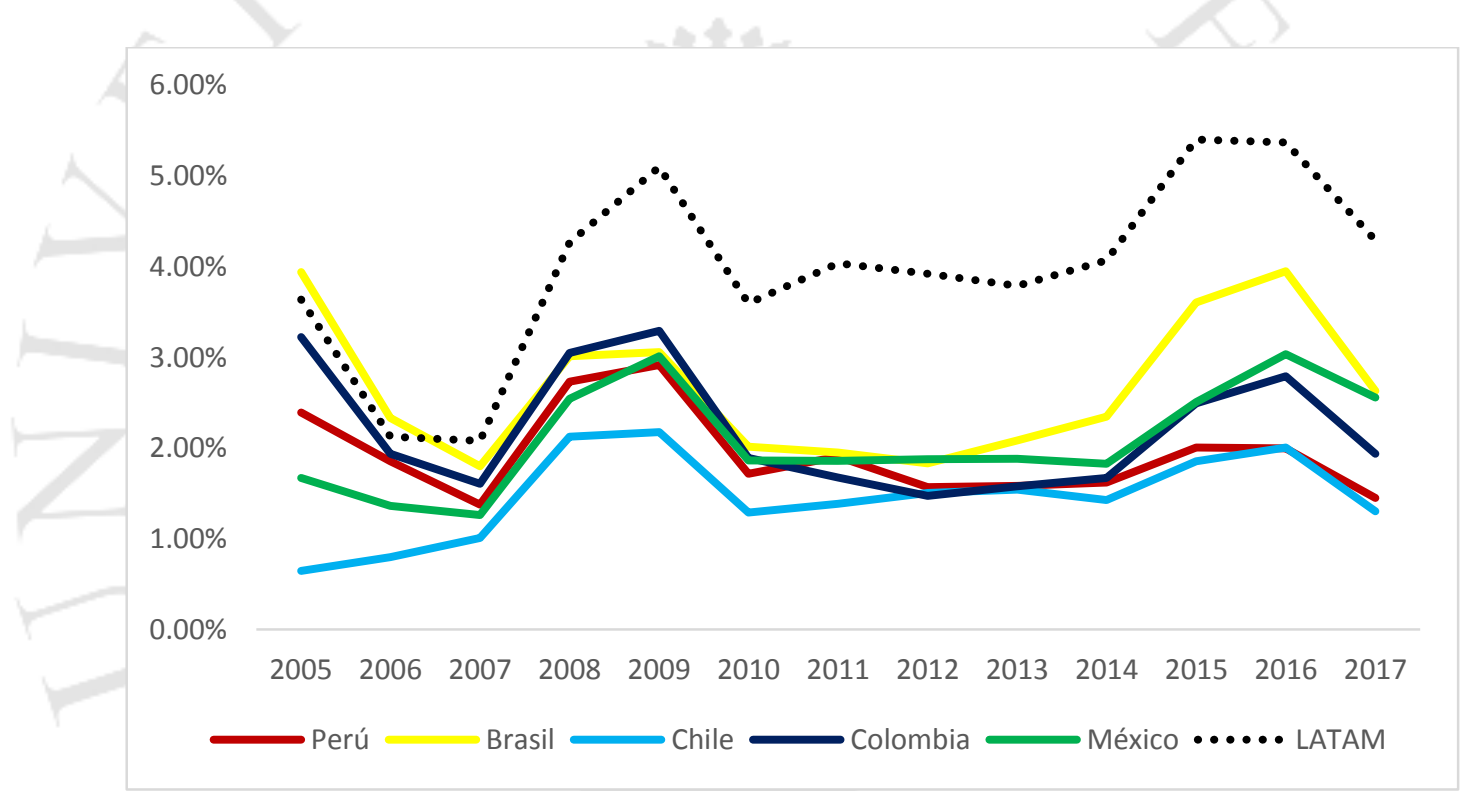

Fuente: Banco Central de Reserva del Perú (s.f.)

Elaboración: Propia

Como se mencionó, podemos observar que los países latinoamericanos han seguido la misma tendencia; no obstante, sí podemos observar también un mejor performance post crisis de Perú, pasando a México y llegando a casi los niveles de Chile, el mejor de la región

${ }^{4}$ Emerging Market Bond Index, es un indicador creado por JP Morgan, el cual mide el riesgo país como la diferencia entre la tasa de interés que paga un bono emitido en dólares por un país emergente y la tasa de interés que paga los bonos de tesoro de Estados Unidos. 


\subsection{El mercado bursátil peruano y su evolución}

\subsubsection{Mercado de valores}

El mercado de valores es una alternativa al sistema bancario, donde las empresas captan directamente de los inversionistas los recursos que necesitan para ejercer sus actividades. La ventaja que obtienen al no recurrir a los intermediarios financieros es un costo de financiamiento más bajo para las empresas captadoras de recursos y un retorno más atractivo para los inversionistas. (SMV Perú, 2015)

Estas empresas que captan recursos pueden ser pequeñas, medianas o grandes. De igual manera, los inversionistas pueden ser institucionales como las AFP y los fondos mutuos o también personas naturales con excedentes que buscan retornos más atractivos a los ofrecidos por el sistema bancario, estos últimos también son conocidos como clientes retail.

Debido a que las grandes empresas son las que captan dinero de los inversionistas y a que nos existen intermediarios financieros, la norma ${ }^{5}$ exige que las empresas revelen información pertinente (estados financieros, memorias anuales, etc.) para que los inversionistas puedan evaluar el riesgo que van a asumir y, por lo tanto, exigir un retorno adecuado.

En el mercado de valores se transan todo tipo de valores negociables como bonos, acciones de capital, acciones de inversión, instrumentos de corto plazo, etc. Esto permite que se ofrezcan diversas alternativas de financiamiento o inversión en términos de rendimiento, liquidez y riesgo.

\subsubsection{Mercado secundario}

El mercado secundario se ocupa de la compraventa de valores que hayan sido emitidos. Estos pueden ser acciones, hipotecas y créditos en general. En el Perú, el mercado secundario más importante es la Bolsa de Valores de Lima (BVL), donde se cotizan acciones de empresas.

\footnotetext{
${ }^{5}$ Título II de la Ley de Mercado de Valores (Transparencia del Mercado)
} 
Es importante que un mercado secundario sea líquido y permita el inversionista transformar los valores en efectivo cuando así lo desee y a un costo razonable. De otro modo, esto podría afectar al mercado primario $\mathrm{y}$, por ende, obstaculizar nuevas emisiones.

\subsubsection{Características de la bolsa de valores}

\subsubsection{Tamaño}

La capitalización bursátil mide el valor del mercado que tiene una empresa inscrita en la Bolsa de Valores y se calcula multiplicando el número de acciones que tiene la empresa por el valor de mercado de la acción. Este indicador, además, sirve para medir el tamaño del mercado bursátil a partir de la suma de las capitalizaciones bursátiles de las bolsas inscritas. Debido a que toma en consideración tanto el número de acciones inscritas en la bolsa como el precio de la cotización, es un buen indicador para medir tanto el tamaño como la rentabilidad del mercado.

\subsubsection{Liquidez}

Para medir la liquidez del mercado bursátil se usa el valor del volumen negociado en millones de dólares (es preferible usar dólares americanos a monedas locales para poder hacer comparaciones en otros mercados). Así mismo, tomando en cuenta las diferencias de tamaño de los diferentes mercados, se puede hacer una comparación relativa usando como indicador de liquidez el volumen negociado entre e PBI del país.

El indicador mencionado refleja de mejor manera la liquidez del mercado, debido a que se espera que tenga un spread con otros países similar al spread que se puede encontrar en el ratio de consumo sobre PBI con estos otros países. (Arispe, 2014)

Otro indicador de liquidez del mercado es la frecuencia de negociación de las acciones, donde un $100 \%$ indica que la acción se negoció todos los días de periodo que se haya consultado ${ }^{6}$.

\subsubsection{Rentabilidad}

Para medir la rentabilidad de un mercado, usualmente se usan los índices bursátiles. Estos índices reflejan la evolución en los precios de los valores que los

\footnotetext{
${ }^{6} \mathrm{La}$ frecuencia de negociación puede ser consultada en periodos mensuales, trimestrales o anuales
} 
componen y usualmente agrupan acciones con alguna característica similar. Algunos tipos de clasificación se mencionan a continuación:

- Por industria

- Por liquidez

- Por capitalización bursátil

- Por ubicación geográfica

- Por buen gobierno corporativo

\subsubsection{Evolución del mercado bursátil peruano}

El mercado bursátil peruano ha mostrado una tendencia creciente sostenida y un mayor dinamismo desde 1990 en adelante. Esto se debe a que se logró una estabilidad política y macroeconómica que permitió un incremento de la inversión extranjera directa, así como el fortalecimiento de las empresas nacionales. Esta tendencia, sin embargo, es más notoria a partir del año 2000, lo cual se explica por el buen desempeño de la economía peruana, así como por las iniciativas para desarrollar el mercado de valores peruano.

Esta tendencia se había mantenido hasta el 2008, donde la incertidumbre generada por la crisis financiera internacional y la caída de los precios de los metales básicos tuvieron un impacto significativo en los principales indicadores de la bolsa peruana. Es así como la capitalización bursátil y el volumen negociado se contrajeron en $47.12 \%$ y $36.4 \%$ respecto al 2007.

No obstante, para el 2009 y el 2010 el mercado bursátil peruano presentó una importante recuperación gracias a medidas como actividades de promoción del buen gobierno corporativo para las empresas peruanas; la integración de las plazas bursátiles de Perú, Chile y Colombia; la solidez de China frente a la crisis y su efecto en el cambio de tendencia en el precio de los metales; y la prórroga para la exoneración del impuesto a la renta para las ganancias de capital producto de las operaciones en bolsa. Esto originó que en el 2010 se alcance el mayor valor histórico de capitalización bursátil, el cual ascendió a 160,867 millones de dólares. 
Figura 6.8

Capitalización bursátil (\% del PBI)

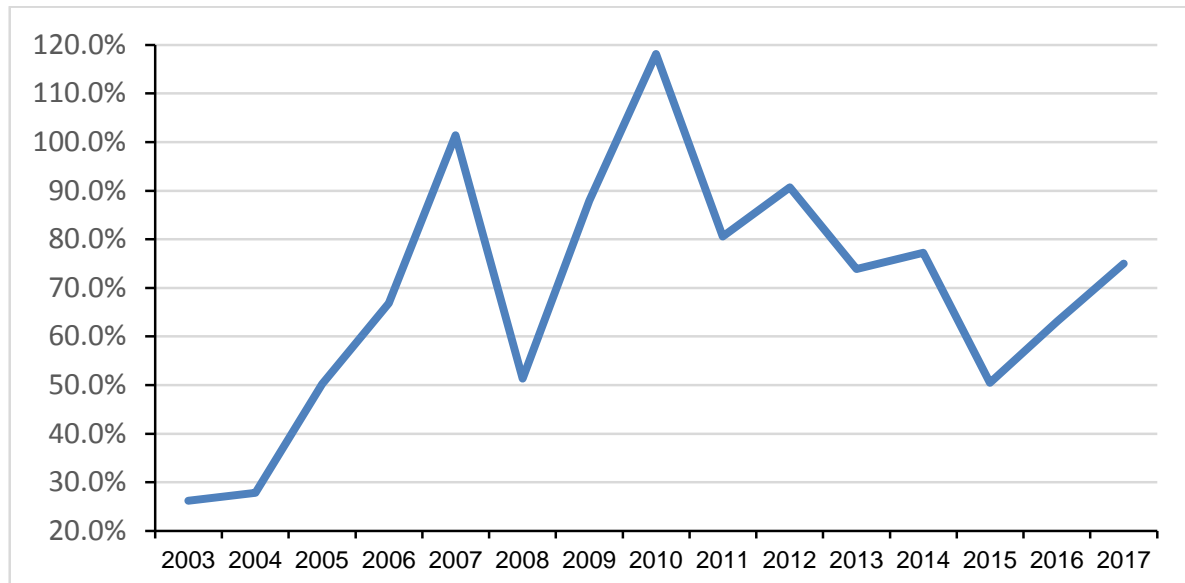

Fuente: Banco Central de Reserva del Perú (s.f.)

Elaboración: Propia

Podemos observar un retroceso en la capitalización bursátil de la bolsa para el año 2008, 2011, 2013 y 2015. A diferencia de los principales indicadores macroeconómicos del país, el efecto de la crisis del 2008 sí impactó de manera inmediata en la bolsa peruana. En el año 2011, la profundización de la crisis europea y la rebaja de la calificación de la deuda de Estados Unidos a AA+ tuvieron un impacto negativo en los mercados bursátiles mundiales, y el peruano no fue la excepción. Por otro lado, en el 2013, la desaceleración de China y el inicio del tapering ${ }^{7}$ por parte de la FED ${ }^{8}$ también afectaron de manera negativa. Por último, en el año 2015, en general, las bolsas se vieron afectadas por la desaceleración China, la caída de las materias primas como el petróleo, la difícil situación de Grecia y un punto en particular que afectó a la bolsa peruana fue la posible reclasificación de "mercado emergente" a "mercado fronterizo" de nuestro mercado bursátil.

Por el lado de la liquidez, esta ha tenido una tendencia diferente a lo observado en los demás indicadores. Como se puede apreciar el efecto post crisis del 2008 fue a la baja, llegando a un punto crítico en el 2015, año en el cual ocurrió el incidente de la posible reclasificación. A pesar del recupero mostrado hacia el año 2017 en términos

\footnotetext{
${ }^{7}$ Reducción del ritmo de inserción de dinero a la economía

${ }^{8}$ Federal Reserve System
} 
nominales, en términos relativos al PBI aún estamos lejos de alcanzar los niveles de 2007, año previo a la crisis.

Figura 6.9

Volumen negociado BVL

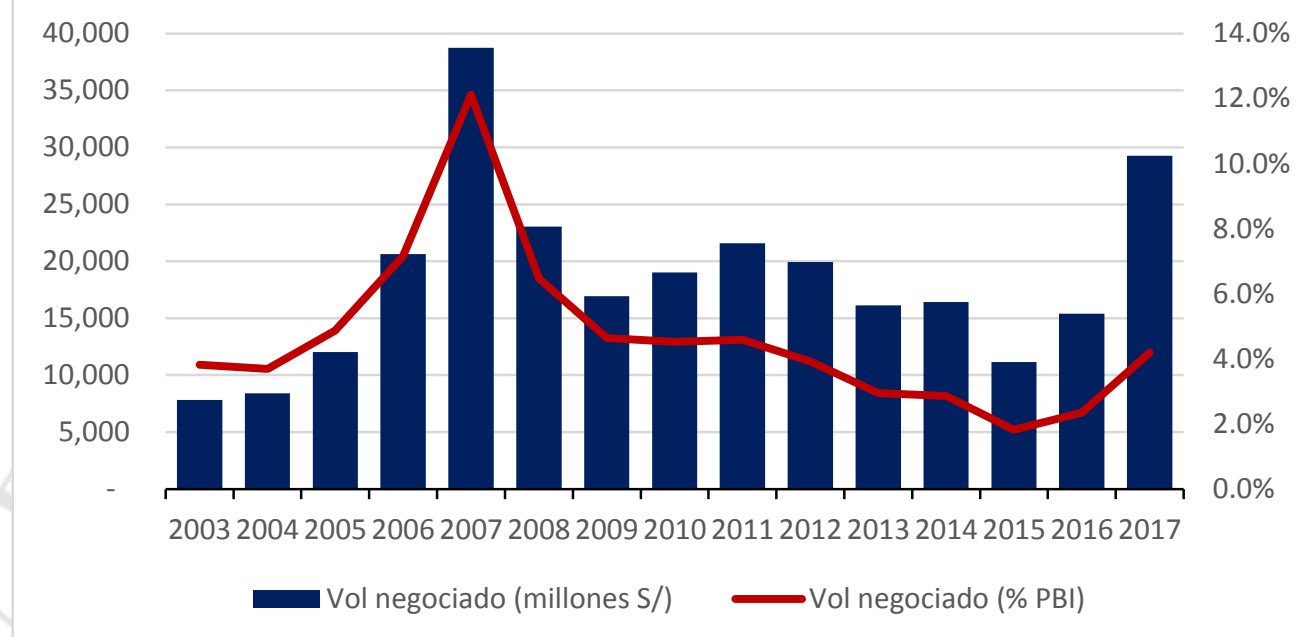

Fuente: Banco Central de Reserva del Perú (s.f.)

Elaboración: Propia

\subsubsection{Evolución y comparación de la BVL con otras bolsas de la región}

Al hacer referencia a la región latinoamericana, es necesario mencionar al Mercado Integrado Latinoamericano (MILA). Iniciativa que empezó en el año 2009 con la integración de las plazas bursátiles de Perú, Chile y Colombia y que a partir de 2011 entró en operación. Posteriormente, hacían finales del 2014 se integró también la Bolsa Mexicana de Valores.

\subsubsection{Tamaño}

Como se mencionó anteriormente, el tamaño se mide con la capitalización bursátil. En el siguiente gráfico se compara el market cap en millones de dólares americanos entre la Bolsa de Valores de Brasil y el MILA. Podemos observar que hasta el 2014, previo al ingreso de la Bolsa Mexicana al MILA, la Bolsa de Brasil superaba largamente, en tamaño, al MILA. No obstante, la entrada de la Bolsa Mexicana y el impacto de por el escándalo de corrupción en Brasil, permitieron que la tendencia se revierta. 
Figura 6.10

BOVESPA vs MILA9 (market cap en US\$ MM)

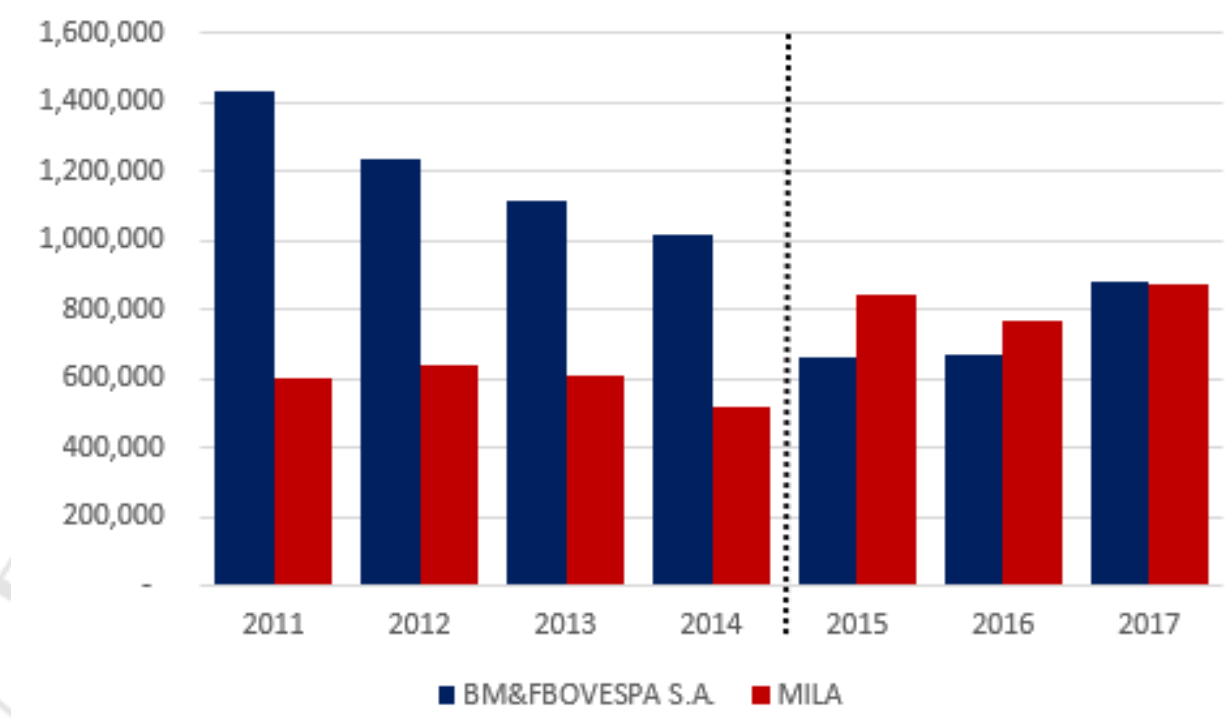

Fuente: World Federation Exchange (s.f.)

Elaboración: Propia

Dado que el MILA congrega a cuatro bolsas, es interesante ver la composición de este.

\footnotetext{
${ }^{9}$ Market cap del MILA como agregado de las bolsas que lo conforman
} 
Figura 6.11

Composición del MILA (market cap en \%)

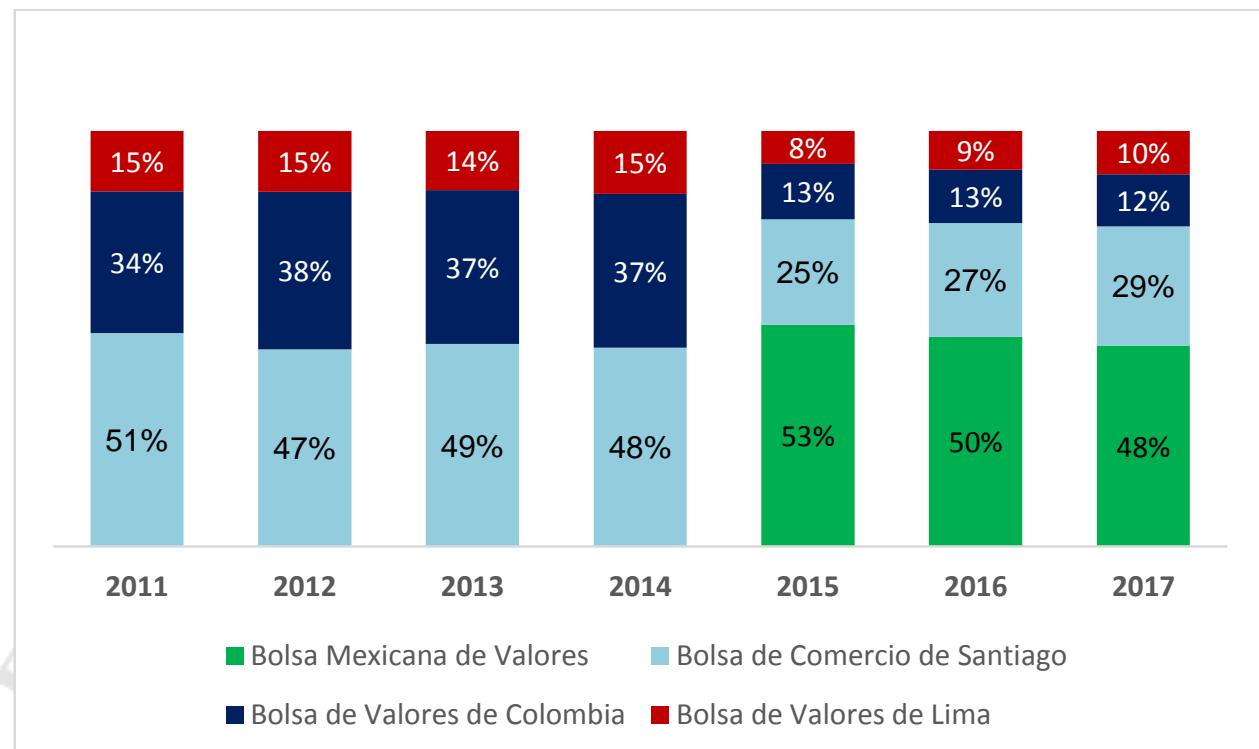

Fuente: World Federation Exchange (s.f.)

Elaboración: Propia

Si bien se observa que la Bolsa de México es la que más aporta al MILA y que la Bolsa Peruana es la que menos aporta, no sería lógico usar esta comparación por la diferencia significativas de tamaño entre los países. Una forma de estandarizar y permitir comparar el tamaño del mercado bursátil entre países es usa la capitalización bursátil entre el PBI del país. 
Figura 6.12

Market Cap region (\% del PBI)

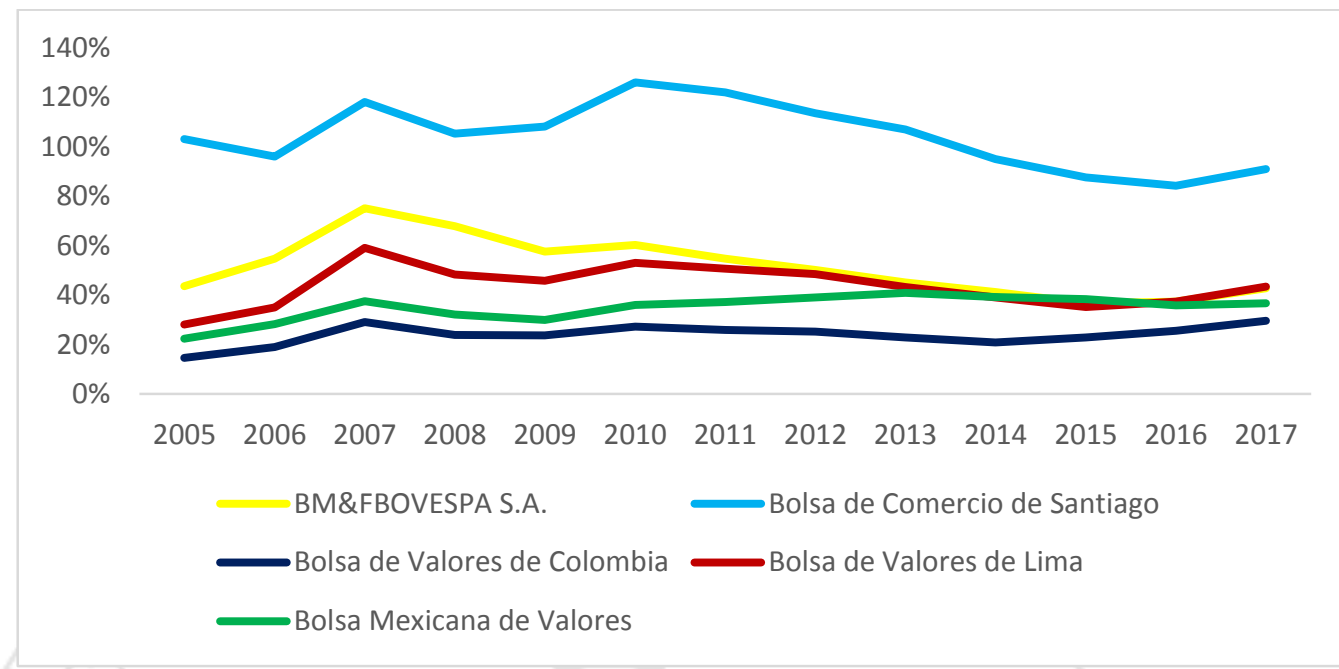

Fuente: World Federation Exchange (s.f.)

Elaboración: Propia

Como podemos observar, si bien el aporte de Perú al MILA es el menor, en términos relativos, tomando en cuenta el tamaño de la economía del país, se puede concluir que nos encontramos, en el nivel promedio de la región en cuanto a tamaño de la bolsa de valores, con excepción de Chile que tiene un mercado bursátil más desarrollado.

Otro factor que resaltar, en cuanto a tamaño, es que el Perú es el tercer país por debajo de Brasil y Chile, con mayor número de compañías que listan en bolsa. 
Figura 6.13

Número de compañías listadas (2017)

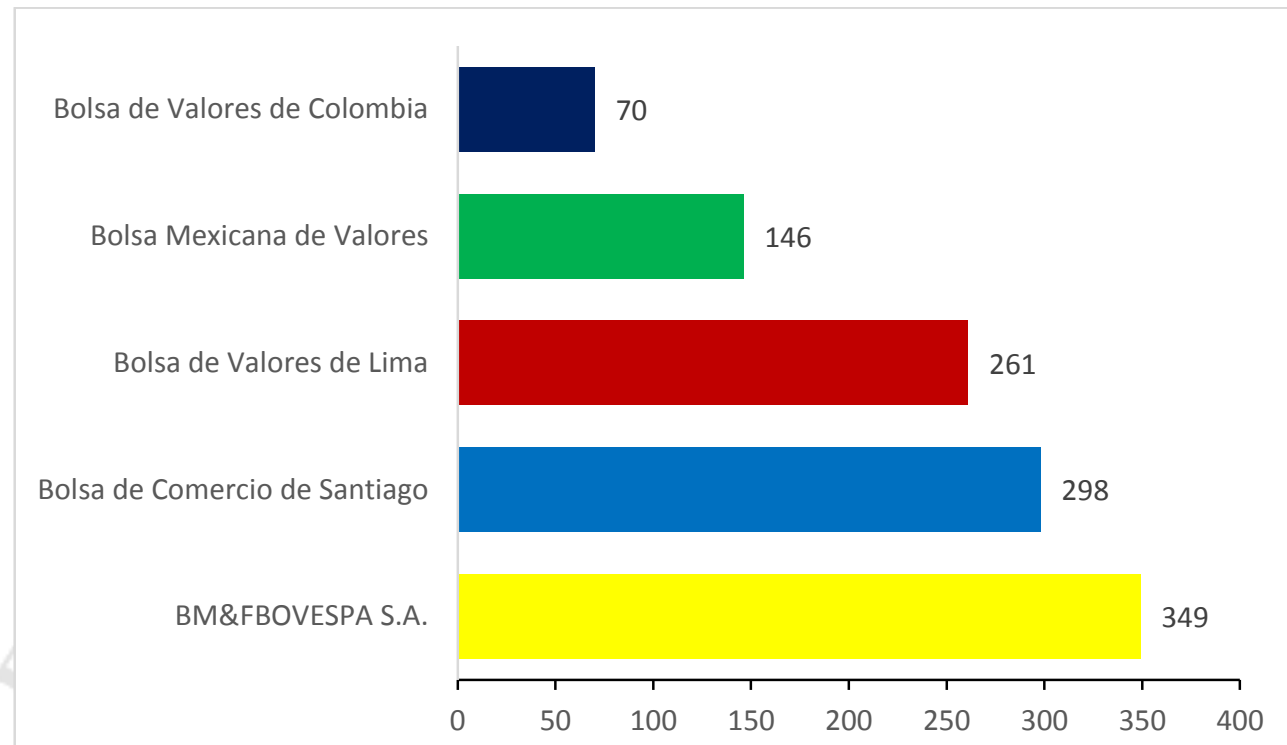

Fuente: World Federation Exchange (s.f.)

Elaboración: Propia

\subsubsection{Liquidez}

Si bien existen diversas maneras de medir la liquidez en el mercado bursátil, la más usada es el volumen de negociación, el cual también se ajusta por el PBI del país, con la finalidad de permitir la comparación.

Figura 6.14

Volumen negociado región (\% del PBI)

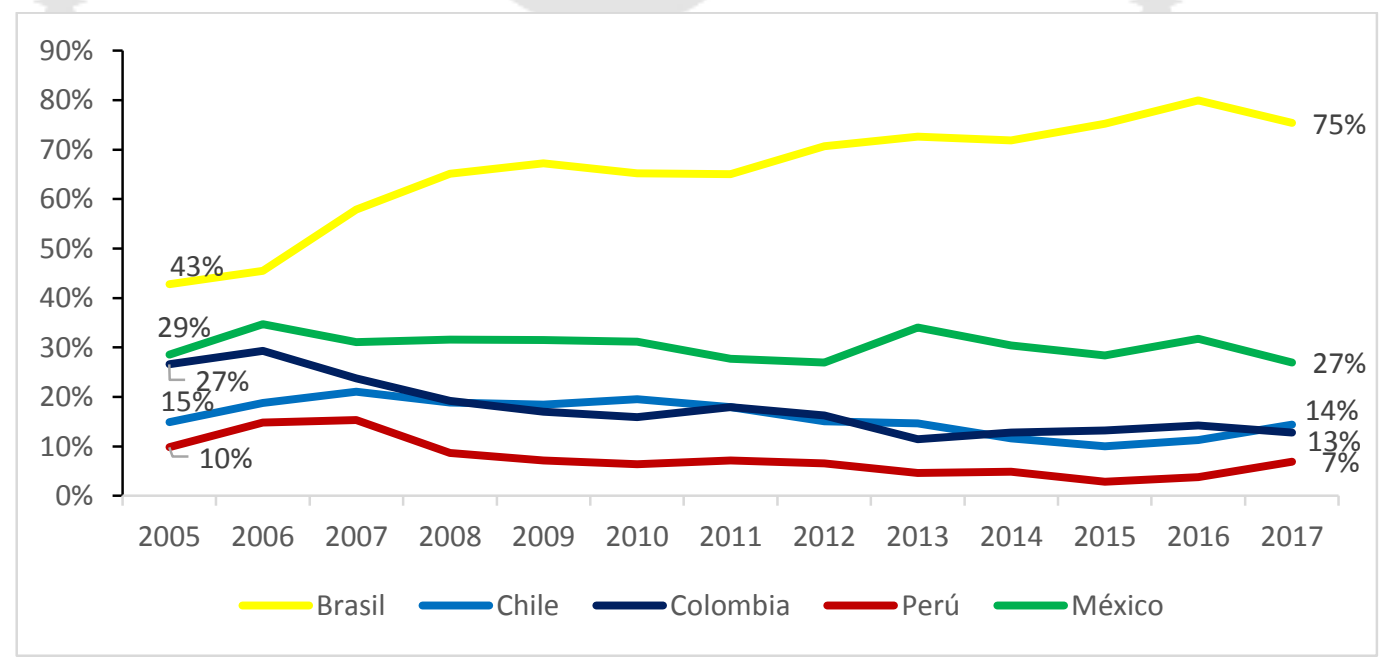

Fuente: World Federation Exchange (s.f.)

Elaboración: Propia 
Se observa que, con excepción de Brasil, las bolsas de la región aún no recuperan los niveles de liquidez precrisis del 2008. Además, el Perú tiene el mayor atraso, en términos relativos, en cuanto a la variable de liquidez en la bolsa de valores. El caso de Brasil ha seguido una tendencia completamente diferente al de la región aumentando su liquidez de manera sostenida a pesar de la crisis del 2008 y del escándalo de corrupción de Odebretch. Esto último, evidencia la mayor cultura financiera de los inversionistas que invierten en la Bolsa de Brasil y mercado más desarrollado, en el sentido que la volatilidad genera oportunidades de generar rentabilidad si es que se tiene el conocimiento y los productos financieros para ello. Mientras que los demás países de la región toman una postura conservadora de no inversión ante momentos de incertidumbre o crisis.

En el caso de Perú, no solo se observa una caída en términos relativos, sino también en términos absolutos, especialmente en el 2015, año en que se afrontó la posible reclasificación a mercado fronterizo. Actualmente, aún no hemos recuperado niveles precrisis. Este factor, es preocupante, pues como se mencionó anteriormente, el Perú ha tenido un crecimiento continuo desde hace 18 años, tendencia que no se refleja en el nivel de liquidez del mercado. Ante un factor favorable a nivel país, se esperaría que los ciudadanos consuman más de todos los bienes, incluidos los productos financieros, al menos en términos nominales. (Arispe, 2014) 
Figura 6.15

Volumen negociado BVL (US\$ MM)

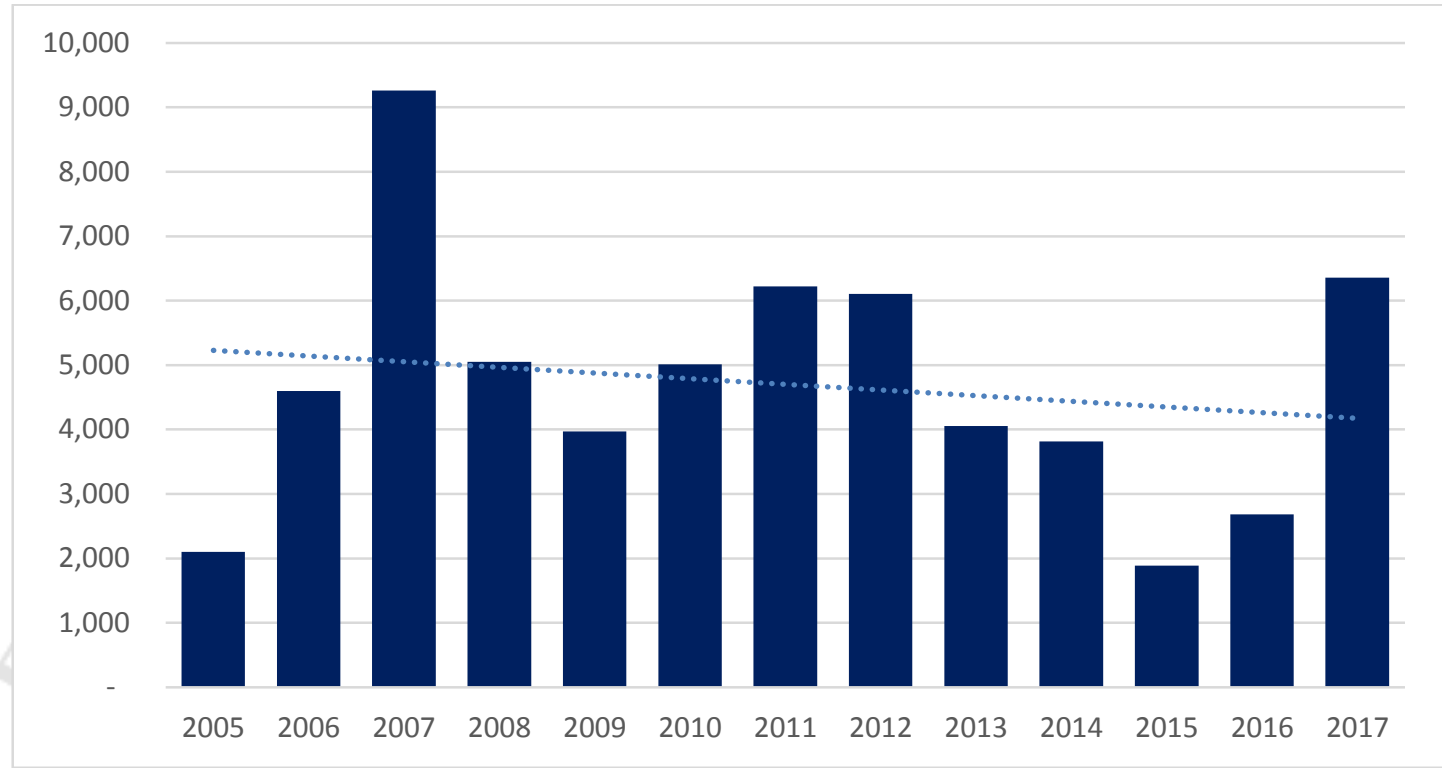

Fuente: World Federation Exchange (s.f.)

Elaboración: Propia

\subsection{American Depositary Receipts (ADRs)}

Según la U.S. Securities and Exchange Commission (SEC), los ADR son certificados negociables que representan la tenencia de American Depositary Shares $(\mathrm{ADS})^{10}$, que a su vez representan la tenencia de acciones de empresas no estadounidenses que han sido depositadas con un banco americano. Los ADRs se negocian en dólares americanos mediante reglas americanas, lo que permite a los inversionistas evitar hacer transacciones en moneda extranjera. Los ADR tienen la ventaja de poder representar un conjunto de acciones o incluso una fracción de una acción, esto con la finalidad de que se le pueda asignar precios típicamente negociados en los mercados americanos.

Los ADR son creados por los bancos depositarios y los inversionistas pueden comprar y vender el mismo en el mercado secundario. Así mismo, si el inversionista lo

10 ADRs y ADSs son usualmente usados de manera indiferente por los inversionistas. Sin embargo, la diferencia entre ambas radica en que los ADR son un paquete de ADSs 
desea, puede cambiar el ADR por las acciones de la empresa extranjera. Los ADR pueden ser de dos tipos:

- Patrocinado: Existe un acuerdo entre la empresa extranjera y el banco depositario para el pago de dividendos, la comunicación a accionistas y todos los servicios asociados a la tenencia de la acción.

- No patrocinado: Es iniciado por un bróker, sin necesidad de haber un acuerdo con la empresa extranjera. Es decir, el bróker se encarga netamente de todos los servicios asociados a la tenencia de la acción.

En ambos casos, sin embargo, es necesario que la empresa extranjera cumpla con los requerimientos de reportería de la SEC.

Así mismo, los ADR se categorizan en tres niveles, que dependerán de la magnitud del acceso al mercado americano por la empresa extrajera:

\section{- Nivel 1}

- No se usa para levantar capital, solo para negociar la acción en mercados $\mathrm{OTC}^{11}$

- Es la única modalidad que puede ser no patrocinada

- A pesar de llenar la forma F-6 de la SEC, la información de la empresa extranjera se encontrará en la página web de la empresa y no en el sistema EDGAR $^{12}$

\section{- Nivel 2:}

- No se usa para levantar capital, solo para negociar la acción en el mercado secundario y establecer presencia en el mercado americano

○ El ADR será inscrito en la bolsa americana de valores

${ }^{11}$ Over the counter: Hace referencia a mercados no organizados

12 Electronic Data Gathering, Analysis, and Retreival o EDGAR es una base de datos pública de la SEC que brinda información de las empresas que, por ley, tienen que presentar formas ante esta institución 
○ Aparte de la forma F-6, tendrá que registrar reportes anuales a través de la forma $20-\mathrm{F}$ de la SEC

\section{- Nivel 3:}

- Se usa para levantar capital, además de poder negociar la acción en el mercado secundario y establecer presencia en el mercado americano

- El ADR será inscrito en la bolsa de valores americano

○ Tendrá que llenar la forma F-1, F-3 y F-4 para poder realizar el proceso de emisión del ADR

- Tendrá que registrar reportes anuales a través de la forma 20-F de la SEC.

\subsubsection{Proceso de emisión de un ADR}

En el proceso de emisión de un ADR empieza con la empresa emisora no americana, la cual contacta a un banco de inversión para el proceso de emisión de nuevos valores. El banco de inversión debe verificar de manera extraordinaria al proceso de emisión en el mercado local que la empresa emisora cumpla con los requisitos de reportería que impone la SEC. Posterior a esto, se contrata un banco custodio local, quien se encargará de custodiar las acciones que serán objeto de los ADR. Paralelamente, se contacta con un banco depositario americano, quién se encargará de la emisión de certificados negociables emitidos en dólares americanos. El banco depositario será quién asuma la responsabilidad frente a los tenedores de los ADR, además de encargarse de proporcionar la información que los inversionistas requieran. Le empresa emisora tendrá la obligación de brindar información relevante sobre obligaciones, derechos y hechos de importancia que puedan afectar a los inversionistas. 
Figura 6.16

Proceso de emisión de un ADR

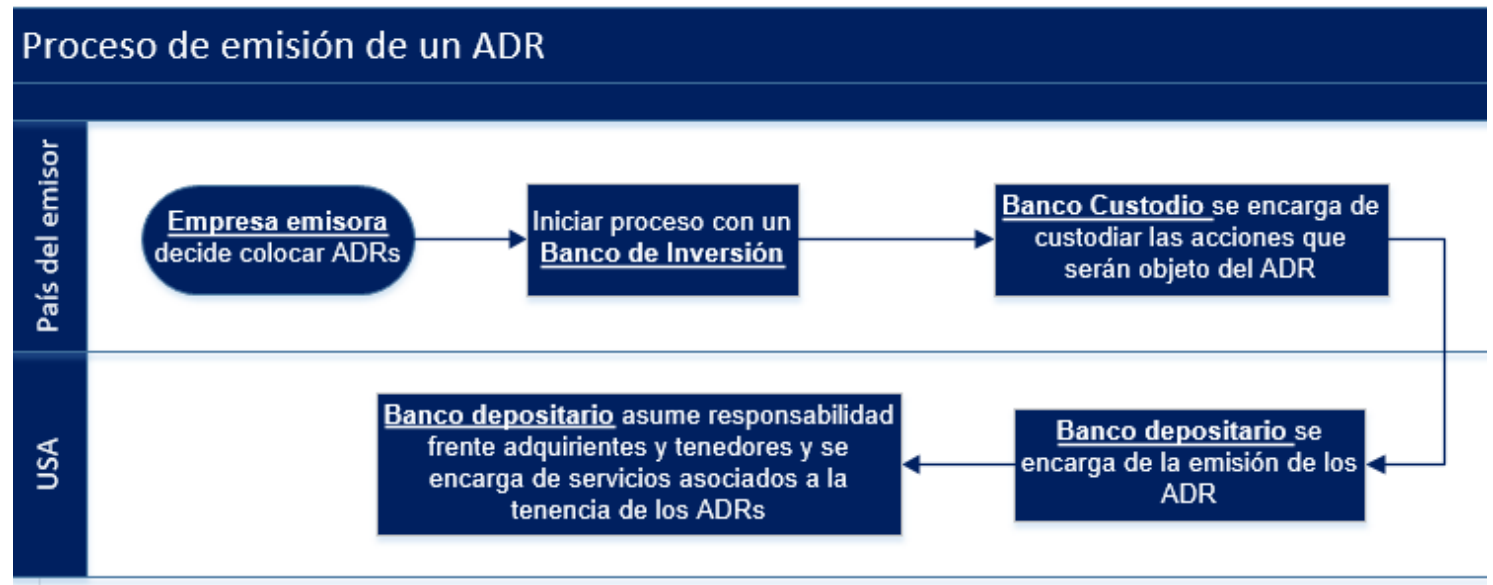

Fuente: Acevedo, Fleisman, Montoya y Mora (2010)

Elaboración: Propia

Por último, los inversionistas podrán adquirir estos valores en el mercado bursátil americano, así como negociar con los mismos

\subsubsection{Ventajas y desventajas de los ADR}

Para poder realizar un mejor análisis de las ventajas y desventajas de la emisión de ADRs, dividiremos a los grupos afectados en cinco:

○ Empresa emisora

En primer lugar, es necesario acotar que, dado los costos y requerimientos de información, son usualmente las grandes corporaciones quienes se encuentran en condiciones de poder iniciar un proceso de emisión de ADRs. Las ventajas que podemos apreciar para la empresa emisora serán el ampliar su base de inversionistas, así como ganar presencia en el mercado americano. Además, al cumplir los requerimientos de reportería de la SEC, estar inscrito en el mercado de valores americano y tener un banco americano que respalda la operación, podrá obtener mejores fuentes de financiamiento. También, en línea con esto, podrá eventualmente, dependiendo el éxito de su acción, realizar emisiones públicas en la bolsa americana aumentando sus posibilidades de levantar mayor capital y a un menor costo. 
Inversionista americano

Los costos de transacción y custodia de un ADR son menores a realizar la inversión en el extranjero, especialmente, por el riesgo de liquidez presente en las bolsas de mercados emergentes. Además, permite a los inversionistas diversificar su portafolio sin tener en su contabilidad valores emitidos en moneda extranjera $y$ con un mayor nivel de transparencia debido a que las empresas extranjeras emisoras deben cumplir con el marco regulatorio de la SEC. Por último, simplifica el cálculo de los impuestos al estar dentro de la jurisdicción impositiva de Estados Unidos y no del país de la empresa emisora.

Una desventaja es que los ADRs no eliminan el riesgo cambiario ni el riesgo país, debido a que son sensibles a variaciones en el precio de la acción subyacente, la cual, a su vez, depende del performance, el riesgo país y el riesgo cambiario de la empresa emisora.

- Mercado de valores americano

El ingreso de ADRs a la bolsa americana podría, potencialmente, aumentar la liquidez de esta. Así mismo, hace más atractiva la bolsa americana al tener mayores opciones de diversificación sin salir de ella.

- Mercado de valores del país de la empresa emisora

Una potencial ventaja sería que la acción de la empresa que emitió un ADR tendría una tendencia a volverse más atractiva, debido a las ventajas que se mencionaron para la empresa emisora, lo cual tendría un impacto sobre su precio y su liquidez.

La principal desventaja, sería la pérdida de acciones que son objeto del $\mathrm{ADR}$, debido a que estas tienen que ser retiradas del mercado afectando indicadores como market cap o liquidez.

- Inversionista del país de la empresa emisora

Debido a las ventajas de la emisión de ADRs, la empresa emisora se hace más atractiva para los inversionistas. Además, la empresa ahora ofrece más información y transparencia debido a los requerimientos de la SEC y, 
por último, ahora los inversionistas tienen la oportunidad de hacer arbitraje debido a que la acción está cotizando en mercados diferentes e incluso, en ocasiones, en monedas diferentes.

La principal desventaja sería la menor cantidad de acciones que habría en el mercado.

\subsection{Principales casos de emisiones de empresas peruanas en el extranjero}

A continuación, se muestran los principales casos de empresas peruanas con emisiones en el extranjero:

\section{Tabla 6.1}

Principales casos de emisiones de empresas peruanas en el extranjero

\begin{tabular}{|c|c|c|c|c|c|}
\hline Empresa & Bolsa & Año de emisión & \# de acciones & Tipo de acción & Obs \\
\hline COPEINCA & Bolsa de Oslo & 2007 & $40,300,000$ & Común & $\begin{array}{l}\text { Acciones que, por características del mercado peruano, se } \\
\text { prefirieron emitir en el extranjero }\end{array}$ \\
\hline Banco de Crédito & NYSE & 1995 & $391,973,951$ & Común & $\begin{array}{l}\text { Intercambio de acciones Bcp (creditc1) por Credicorp } \\
\text { (BAP) a razón de } 0.10401\end{array}$ \\
\hline Telefónica del Perú & NYSE & 2000 & $20,121,703,360$ & ADR & $\begin{array}{l}\text { Intercambiod de acciones TdeP por TEF a razón de } 7 \text { ADSs } \\
\text { por } 290 \text { acciones de TdeP }\end{array}$ \\
\hline Buenaventura & NYSE & 1996 & $11,800,000$ & ADR & $\begin{array}{l}\text { Se inscribieron } 5.9 \text { MM de ADRs a razón de } 1 \text { ADR por cada } \\
2 \text { acciones de BVN }\end{array}$ \\
\hline Graña y Montero & NYSE & 2013 & $97,674,420$ & ADR & $\begin{array}{l}\text { Graña y Montero realizó una OPI en el } 2013 \text { de } 19.5 \text { MM } \\
\text { de ADRs, cada ADR equivalentes a } 5 \text { acciones de Gramon }\end{array}$ \\
\hline Cementos Pacasmayo & NYSE & 2012 & $103,755,460$ & $A D R$ & $\begin{array}{l}\text { Pacasmayo realizó una OPI en el } 2012 \text { de } 20.8 \mathrm{MM} \text { de } \\
\text { ADRs, cada ADR equivalentes a } 5 \text { acciones de Pacasmayo }\end{array}$ \\
\hline
\end{tabular}

Fuente: Telefónica, COPEINCA, Banco de Crédito, Buenaventura, Graña y Montero,

Cementos Pacasmayo

Elaboración: Propia 


\section{ANÁLISIS Y DISCUSIÓN DE RESULTADOS}

Tras haber descrito todos los puntos relevantes para este caso de estudio, se procede a realizar el análisis y discusión de los resultados.

En nuestro primer objetivo planteábamos la comparación entre los indicadores país y los indicadores bursátiles. En este sentido, podemos observar que, según lo descrito, el Perú, de manera general, ha mostrado resultados favorables a lo largo de los últimos 18 años. Se tiene un país con un crecimiento anual ininterrumpido (incluso en años post crisis del 2008), una inflación que, si bien no siempre se mantiene dentro de los márgenes de tolerancia, tampoco tiene variaciones abruptas, lo que refleja la estabilidad económica alcanzada por el país. Así mismo, se observa una tendencia decreciente en la tasa de desempleo y una reducción muy importante en los niveles de pobreza del país, a pesar del aumento de la brecha de desigualdad. Todos estos indicadores, en conjunto, nos demuestran el buen momento económico que ha atravesado el país durante los últimos 18 años, lo cual se ve reflejado en la reducción del riesgo país. Este indicador es importante porque otorga no solo un proxy del performance del país, sino también un reflejo de cómo es percibido el país desde fuera. En este caso, el Perú pasó de estar detrás de México y Chile en el 2005 a superar a México y alcanzar a Chile para el 2017, país líder en la región.

Ante este panorama macroeconómico favorable, surge la pregunta ¿Cómo es, entonces, que, en el 2015, el Perú estuvo cerca de ser reclasificado de "mercado emergente" a "mercado fronterizo"? Para responder a esta pregunta, es necesario hacer el análisis de los indicadores bursátiles. Los indicadores del mercado bursátil peruano muestran una clara tendencia al alza en los años precrisis (2007 hacia atrás), al punto que, en el 2007, se tiene, en términos absolutos, el mayor volumen negociado histórico y la segunda mayor capitalización bursátil histórica. En sentido contrario, en los años post crisis se observa una tendencia a la baja, con excepción de los años 2009 y 2010 para la capitalización bursátil. Es en este último año donde se observa la mayor capitalización bursátil histórica (USD 168,867 MM). Esto se debe a que la bolsa peruana es predominantemente minera y es en estos años en que China empieza a demandar una gran cantidad de materia prima no energética, es decir, metales. Además, para el 2010, se crea 
el MILA, el cual genera bastante expectativa para los mercados de Chile, Colombia y Perú. No obstante, a pesar de esto, la liquidez del mercado sí muestra una caída para estos años.

Para determinar de mejor manera la situación del mercado bursátil peruano y, de acuerdo con nuestro segundo objetivo planteado, se compara los indicadores bursátiles del mercado peruano con los principales mercados de la región. Para ello, al haber diferencias de tamaños entre los mercados, se procede a usar índices en términos relativos expresados como porcentajes del PBI de cada país. Podemos observar que el market cap como porcentaje del PBI de Chile llega a casi el 100\%, mientas que el mismo indicador para México, Colombia, Brasil y Perú oscila entre el 30\% y el 40\%. Podríamos concluir que, en términos de tamaño, el Perú se encuentra dentro del promedio de los mercados de la región. En cuanto a la liquidez del mercado, se analiza mediante del volumen negociado expresado como porcentaje del PBI del país. En este caso, podemos observar que Brasil se encuentra muy por encima del resto con un $75 \%$, seguido de México con $27 \%$, Chile con $14 \%$, Colombia con $13 \%$ y Perú con $7 \%$, Cabe resaltar que, para este indicador, Perú siempre se ha encontrado por debajo de los demás y que aún no se recuperan los niveles precrisis del 2007.

Habiendo comparado y analizado el panorama macroeconómico del Perú, los indicadores bursátiles del mercado peruano y de los principales mercados de la región, podemos concluir que, ciertamente, existe un nivel de atraso en la liquidez del mercado bursátil, pues esta no sigue la misma tendencia que el performance económico del país ni el de otros indicadores bursátiles. Este último punto es realmente preocupante, teniendo en cuenta que tanto el maket cap como el volumen negociado tienen al precio como una de sus variables y que habiendo alcanzado en el 2010 el mayor market cap histórico, el volumen negociado no haya alcanzado ni siquiera los niveles del 2006.

Siguiendo con el tercer objetivo planteado, se analiza los efectos de las emisiones extranjeras para los diferentes agentes que intervienen en la operación. Dado que los beneficios de emisiones en el extranjero para las empresas emisoras y los inversionistas son de amplio análisis y que el aporte de este caso de estudio en este tópico se encuentra en poner sobre la mesa el impacto que se genera sobre la bolsa del país de la empresa emisora, se procederá a ahondar en este punto. Las emisiones en mercados extranjeros tienen básicamente dos impactos sobre las bolsas del país emisor. En primer lugar, las 
emisiones nivel 1 y nivel 2 consiguen "secar" la acción. Si bien este término es usualmente utilizado cuando, mediante recompra de acciones, se reduce el número de acciones en negociación también aplica para los casos en mención, dado que, si bien las acciones siguen en negociación, lo están en otro mercado; por lo que, para términos prácticos, tiene el mismo efecto que una recompra de acciones. Es cierto que muchas veces estos ADRs también cotizan en la bolsa del país de la empresa emisora; sin embargo, suelen ser cantidades residuales. Ahora, las emisiones nivel 3 o las emisiones privadas tiene un efecto indirecto sobre la bolsa local, en el sentido que, por ejemplo, una emisión de una empresa peruana en un mercado extranjero es una emisión que podría haberse hecho en la Bolsa de Valores de Lima, pero que por términos de prestigio, acceso a mejores fuentes de financiamiento y mayor monto de recaudación se realiza en un mercado extranjero. A continuación, dos ejemplos emblemáticos de "secado" por emisiones extranjeras, aunque se debe hacer la aclaración que ambos casos corresponde a intercambios por procesos de unificación:

Figura 7.1

Volumen negociado Banco de Crédito del Perú (US\$ MM)

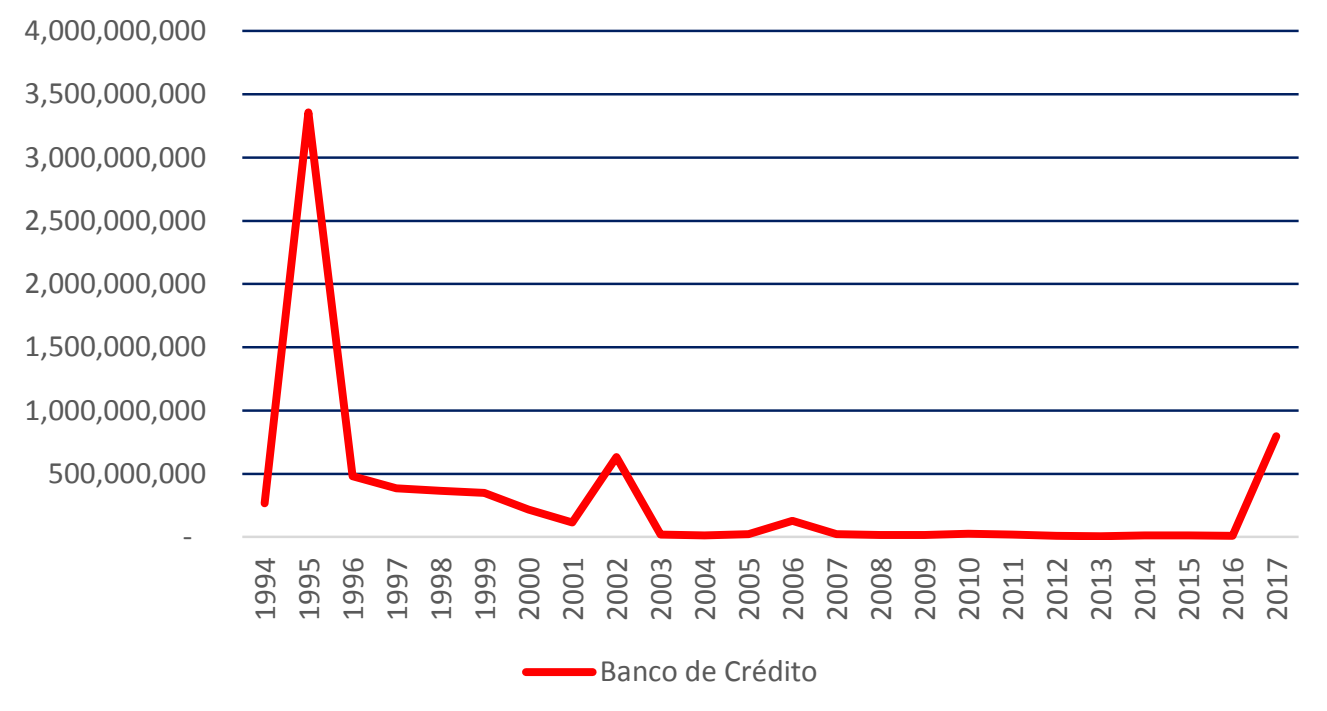

Fuente: Bloomberg (2018)

Elaboración: Propia 
Figura 7.2

Volumen negociado Telefónica del Perú (US\$ MM)

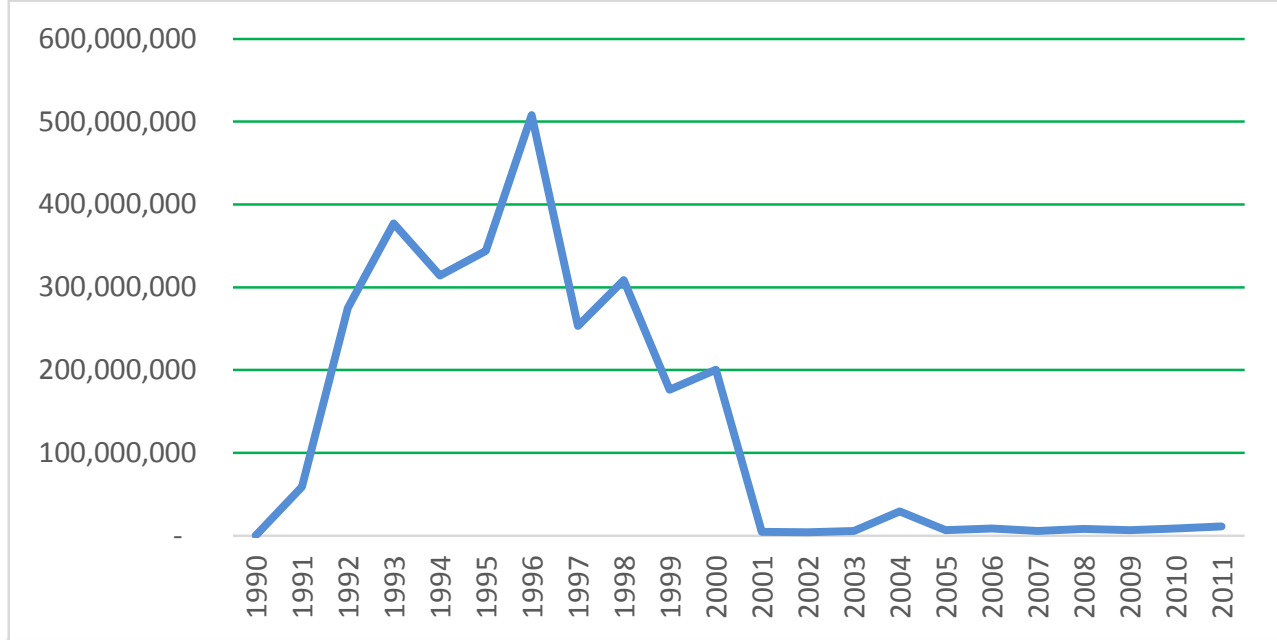

Fuente: Bloomberg (2018)

Elaboración: Propia

Como se puede observar, se ve un menor volumen de negociación, en ambos casos, posterior al intercambio de acciones (1995 para Banco de Crédito y 2000 para Telefónica). Así mismo, colocar dos ejemplos de las diferencias en volúmenes negociados de una misma acción inscrita en la NYSE y la BVL.

Figura 7.3

Volumen negociado Buenaventura ADR (US\$ MM)

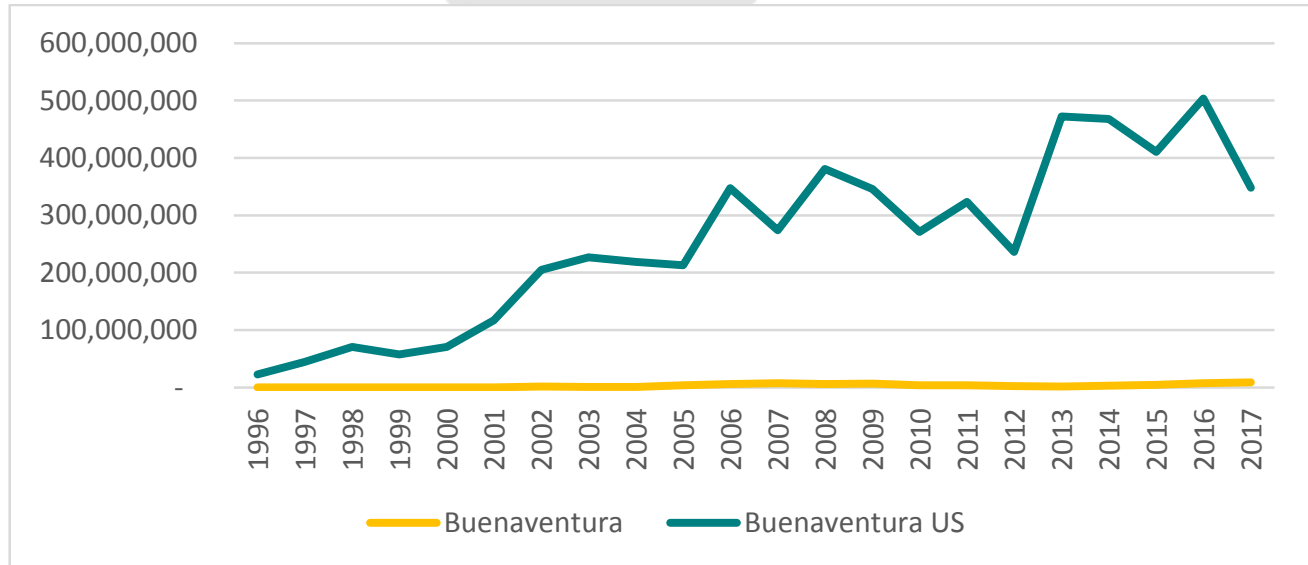

Fuente: Bloomberg (2018)

Elaboración: Propia 
Figura 7.4

Volumen negociado Credicorp (US\$ MM)

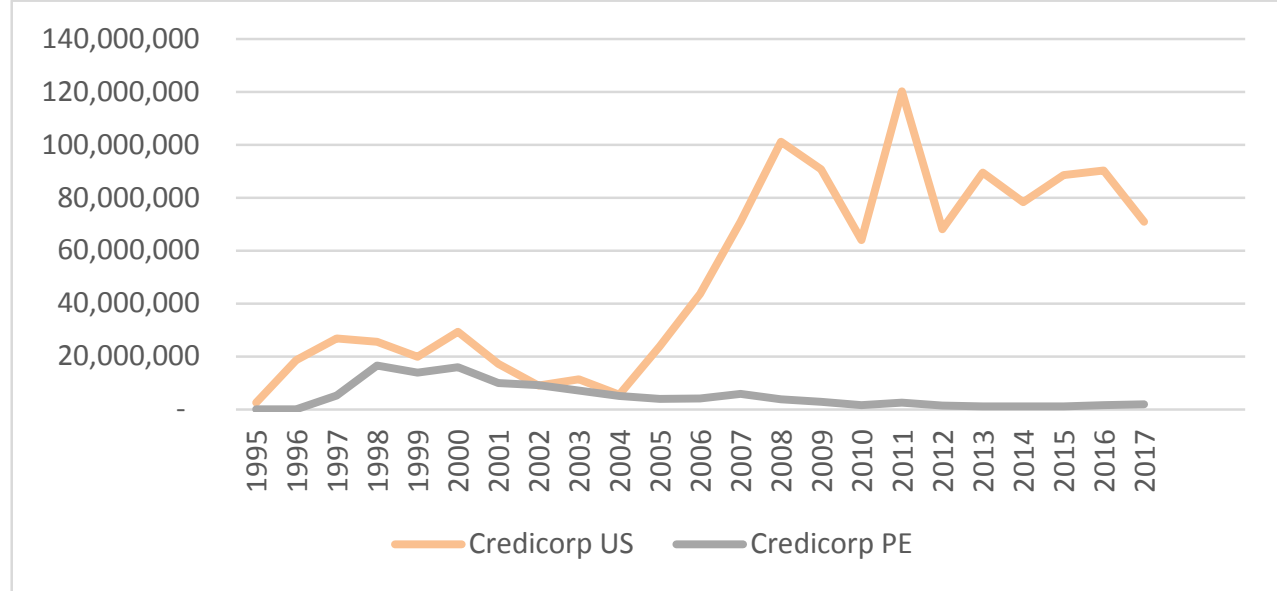

Fuente: Bloomberg (2018)

Elaboración: Propia

En ambos casos se observa que el volumen de negociación difiere en gran medida dependiendo de en qué bolsa se esté negociando.

Este efecto negativo de las emisiones de empresas peruanas en mercados extranjeros se ve potenciado por la estructura empresarial peruana, debido a que solo el $0.6 \%$ del total de empresas en el Perú son grandes y medianas.

Tabla 7.1

Estructura empresarial Perú 2016

\begin{tabular}{|c|c|c|c|c|}
\hline \multirow{2}{*}{ Segmento empresarial } & \multirow{2}{*}{2015} & \multicolumn{2}{|c|}{2016} & \multirow{2}{*}{$\begin{array}{r}\operatorname{Var} \% \\
2016 / 15\end{array}$} \\
\hline & & Absoluto & Porcentaje & \\
\hline Total & 2042992 & 2124280 & 100,0 & 4,0 \\
\hline Microempresa & 1933525 & 2011153 & 94,7 & 4,0 \\
\hline Pequeña empresa & 89993 & 92789 & 4,4 & 3,1 \\
\hline Gran y mediana empresa & 12494 & 13031 & 0,6 & 4,3 \\
\hline Administración pública & 6980 & 7307 & 0,3 & 4,7 \\
\hline
\end{tabular}

Fuente: Instituto Nacional de Estadística e Informática (s.f.) Elaboración: INEI

Teniendo en cuenta que la mayoría de empresas peruanas, incluso las grandes empresas y las corporaciones son, en su mayoría, familiares, acceder al mercado de valores tiene costos altos debido a la apertura y a la estandarización de información, así como el reporting necesario para los inversionistas. Esto establece un circulo vicioso 
generado por el difícil acceso al mercado de valores para las empresas peruanas, la poca liquidez del mercado que no es atractivo para el inversionista debido a la dificultad de liquidar posiciones a precio razonable, la falta de motivación de las pocas empresas que están en condiciones de acceder a un mercado de valores ilíquido ante la incertidumbre sobre si su OPI será exitosa, la falta de motivación de empresas que ya se encuentran en el mercado de valores de realizar nuevas emisiones dada la poca cantidad de inversionistas y la poca liquidez del mercado, los incentivos de las empresas más consolidadas y con acciones muy líquidas de hacer ADRs o emisiones en mercados extranjeros, con la finalidad de generar interés por parte de inversionistas extranjeros para hacer une emisión exitosa posteriormente. Esto nos revela que existe un problema de profundidad no solo de inversionistas, si no también de empresas listadas en la bolsa de valores. 


\section{RECOMENDACIONES}

Si bien la BVL y la SMV han tomado un conjunto de medidas desde el 2015 para mejorar la liquidez y la profundidad del mercado bursátil; sin embargo, estas mejoras están orientadas a los inversionistas. Actualmente, Omar Gutiérrez, Superintendente adjunto de Supervisión Prudencial de la SMV, indica que están trabajando en mejorar sus costos como, por ejemplo, en las comisiones por operación que generan cobros para la SMV, la BVL, CAVALI y las SABs. De igual manera, planean reducir las comisiones de las SABs, pues rondan alrededor del $0.5 \%$ y $1 \%$ del valor de la operación. (Miranda, 2018)

Considero que tanto la SMV y la BVL pueden paralelamente trabajar con, por ejemplo, las empresas que se encuentran en el Mercado Alternativo de Valores (MAV), pero con un objetivo claro, asesorarlos para realizar emisiones en el mercado de valores en un plazo de 5 a 7 años.

Por último, dado que uno de los grandes problemas del sector empresarial peruano es su aversión para brindar información a terceros, debería haber un trabajo en conjunto con el Gobierno para fomentar el reporting en pequeñas y medianas empresas. Empezar a poner condiciones para otorgar créditos a mypes condicionado a que se cumplan un reporting básico, pero brindar un periodo de adecuación para no afectar el sector bancario ni el crecimiento de las mypes. 


\section{REFERENCIAS}

Acevedo, Fleisman, Montoya y Mora (2010). Generalidades de los ADRS: Un estudio de caso sectorial para empresas de Colombia, México, Brasil y Chile. Ecos de $\begin{array}{llll}\text { Economía, } & \text { 64-97. } & \text { Recuperado de }\end{array}$ https://www.redalyc.org/articulo.oa?id=329027266004

Arispe, A. (28 de abril de 2014). ¿Por qué la bolsa peruana es tan ilíquida? [mensaje en un blog]. Recuperado de http://semanaeconomica.com/viva-labolsa/2014/04/28/por-que-la-bolsa-peruana-es-tan-iliquida/

Arispe, A. (03 de junio de 2015), Nuevos índices en la BVL... ¿cuál es cuál? [post en un blog]. Recuperado de http://semanaeconomica.com/viva-labolsa/2015/06/03/nuevos-indices-en-la-bvlcual-es-cual/

Banco Central de Reserva del Perú (s.f.). BCRP Data. Recuperado de https://estadisticas.bcrp.gob.pe/estadisticas/series/

Bloomberg L.P. (2018). Stock price graph [Gráfico de precios de una acción]. Recuperado 19 de noviembre de 2018 de la base de datos de Bloomberg.

Comisión Económica para América Latina y el Caribe (2018). Anuario Estadístico de América Latina y el Caribe 2017 (LC/PUB.2018/2-P). Recuperado de http://interwp.cepal.org/anuario_estadistico/Anuario_2017/index-en.htm

Instituto Nacional de Estadística e Informática (s.f.). Base de datos estadística. Recuperado de https://www.inei.gob.pe/

Miranda, M. (27 de abril de 2018). Mercado bursátil: SMV avanza en esfuerzos para bajar costos en breve y dinamizar bolsa. Andina. Recuperado de https://andina.pe/agencia/noticia-mercado-bursatil-smv-avanza-esfuerzos-para-bajarcostos-breve-y-dinamizar-bolsa-708092.aspx

SEC (U.S. Securities Exchange Commission) (2012). Investor bulletin: American Depositary Receipts. Recuperado de https://www.sec.gov/investor/alerts/adr-bulletin.pdf

World Federation of Exchanges (s.f.). Reportes mensuales. Recuperado de https://www.world-exchanges.org/our-work/statistics 
SMV Perú (05 de marzo de 2015). 1 SMV ¿Qué es el Mercado de Valores y Cuál es su rol? [archivo de video]. Recuperado de https://www.youtube.com/watch? $\mathrm{v}=0$ wf0sdH118\&list=PLsTHATbFjBCsDhKfUVWAgnjQzpd8mBw3T

Zapatero, M. A. (s.f.). Desempeño y perspectivas: Evaluación del mercado accionario peruano por MSCI. Recuperado de https://drive.google.com/open?id=1XCXjbeBamvRJn3ZloW6NAt92tIVy81sQ

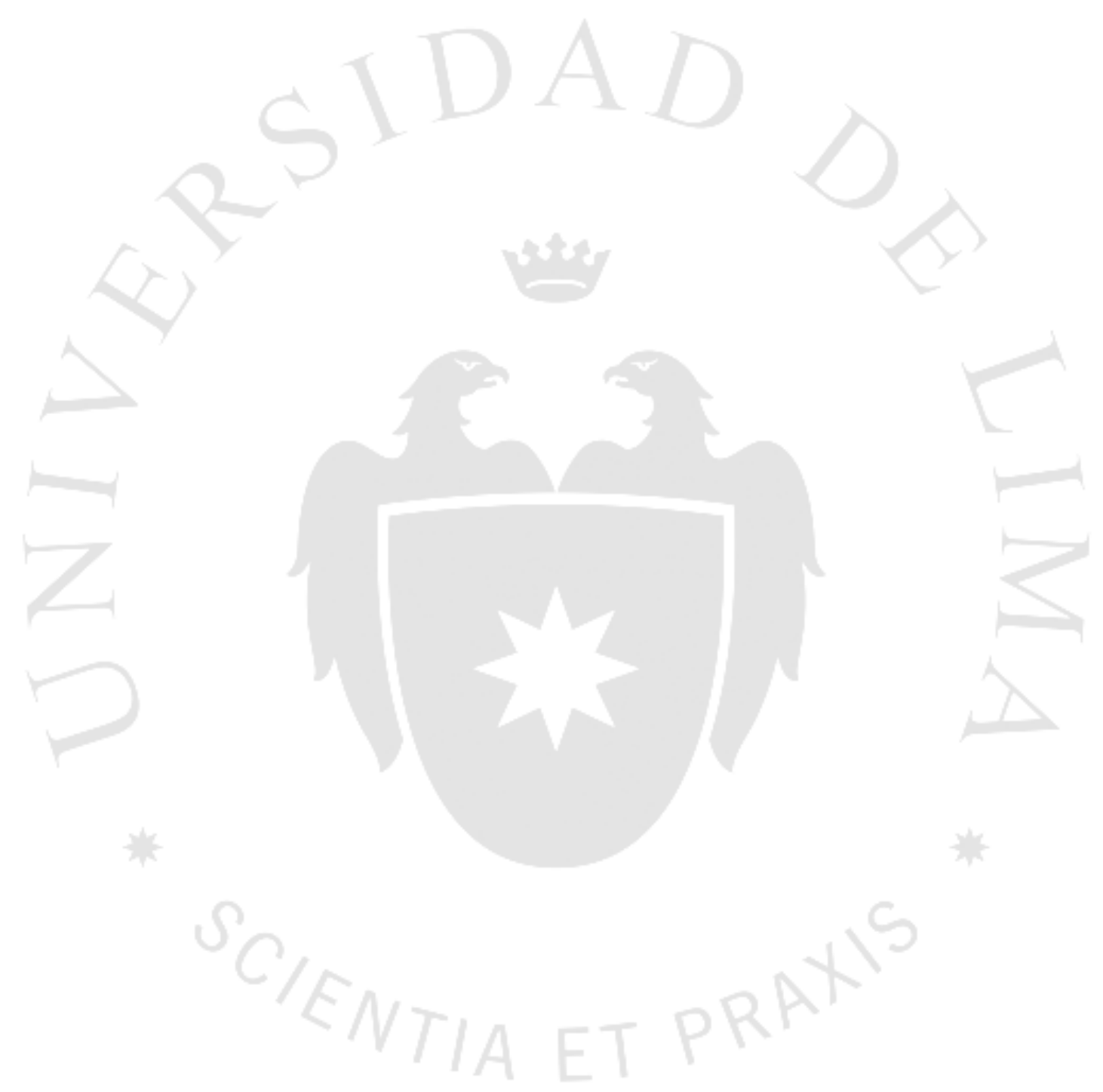




\section{BIBLIOGRAFÍA}

Bonelli Urquiaga, G. (1999), Algunos alcances sobre los ADRs en el sistema financiero. Recuperado

de

http://revistas.pucp.edu.pe/index.php/iusetveritas/article/view/15857 


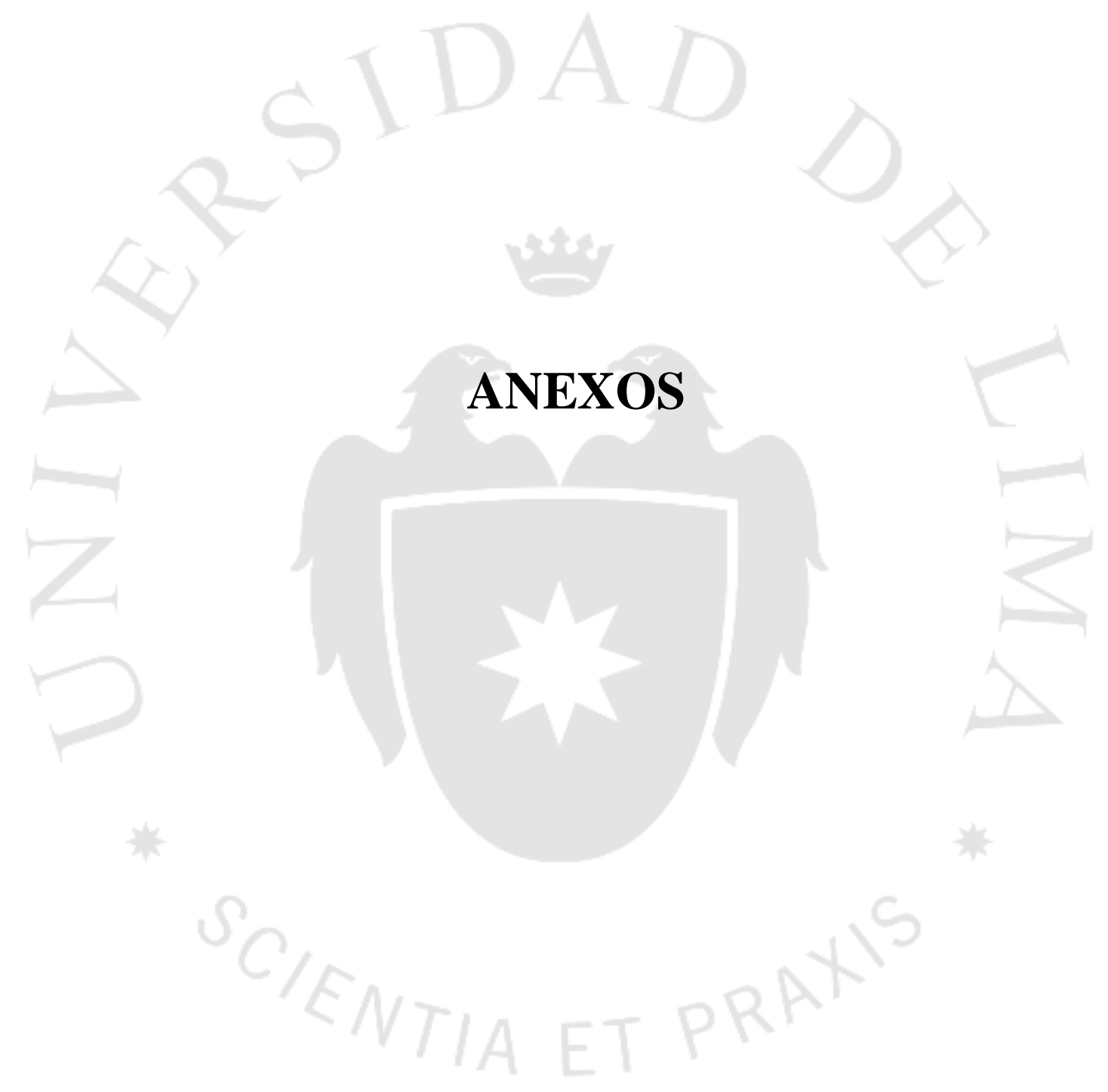




\section{Anexo 1: Volumen negociado 1970-2017}

\begin{tabular}{|c|c|c|c|c|c|c|c|c|c|c|c|c|c|c|c|c|c|c|c|c|c|c|c|c|}
\hline \multicolumn{13}{|c|}{$1970 \cdot 2017$} & & & & & & & & & & & 1970 & -2017 \\
\hline \multirow[t]{2}{*}{ AAOO } & \multicolumn{12}{|c|}{ EN MIILONES DE SOLES CONSTANTES(I) } & \multicolumn{12}{|c|}{ EN MIILOKES DE DOLARES(?) } \\
\hline & variable & $\begin{array}{l}\text { Mudo.de } \\
\text { Subastas }\end{array}$ & $\begin{array}{l}\text { Mdo. de } \\
\text { Dineroro }\end{array}$ & \begin{tabular}{l|l} 
Mato. \\
Contruno
\end{tabular} & \begin{tabular}{l|l} 
Total \\
\end{tabular} & $\begin{array}{l}\text { Renta } \\
\text { Vartable }\end{array}$ & $\begin{array}{l}\text { Instr. Pritstamo } \\
\text { de Devula de Valares }\end{array}$ & Total & \begin{tabular}{c|c} 
con \\
Prima
\end{tabular} & Primaria & MIEM⿻ & $\begin{array}{l}\text { NEGoCAADo } \\
\text { SOLESII) }\end{array}$ & variable & \begin{tabular}{|l|}
$\begin{array}{l}\text { Mdo. de } \\
\text { subastas }\end{array}$ \\
\end{tabular} & $\begin{array}{l}\text { Modo.de } \\
\text { Dinero }\end{array}$ & \begin{tabular}{l|l} 
Mado \\
Contituou
\end{tabular} & Total & $\begin{array}{l}\text { Renta } \\
\text { Vartable a }\end{array}$ & $\begin{array}{l}\text { Instr. Pristamo } \\
\text { de Deuda de Valores }\end{array}$ & Fotal & $\begin{array}{c}\text { con } \\
\text { Prima }\end{array}$ & $\mid$\begin{tabular}{l|} 
Coloce \\
Primarial
\end{tabular} & MENM & 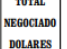 \\
\hline 1970 & 1402 & & 114.7 & & 1447 & & & & & & & 2849 & 16.8 & & 13.8 & & 13.8 & $\because$ & & & & & & \\
\hline 1971 & 1462 & $\because$ & 120.4 & & 120.4 & 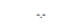 & $\approx$ & & & 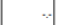 & & 266.6 & 18.7 & $\approx$ & 15.3 & & 15.3 & $\because$ & 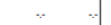 & & & & & 340 \\
\hline 1972 & 176.8 & $\because$ & 92.1 & & 92.1 & $\because$ & $\%$ & & & $\because$ & & 2689 & 24.1. & $\%$ & 12.6 & & 126 & 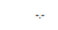 & $\%$ & & & & & 36.7] \\
\hline 1973 & 1423 & $\approx$ & 96.4 & & 96.4 & $\%$ & 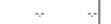 & & & & & 2387 & 21.2 & $\therefore$ & 14.4 & & 14.4 & $\%$ & $\approx$ & & & & & 356 \\
\hline 1974 & 1227 & $\because$ & 823 & $\because$ & 82.3 & $\%$ & $\because$ & & & $\because$ & 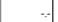 & 2050 & 21.3 & $\because$ & 14.4 & & 14.4 & $\%$ & $\because$ & & & & & 35.7] \\
\hline 1975 & 421. & $\%$ & 78.6 & & 78.6 & $\%$ & $\%$ & & & & & 120.7 & 8.7 & $\approx$ & 16.3 & & 16.3 & $\%$ & $\approx$ & & & & & 250.0 \\
\hline 1976 & 51.7 & $\because$ & 85.5 & $y$ & 85.5 & . & $\because$ & & & & $\therefore$ & 1372 & 10.5 & $\approx$ & 17.3 & & 173 & $\because$ & $\approx$ & & & & & 278 \\
\hline 197 & 137.8 & $\cdots$ & 653 & & 65.3 & $\because$ & 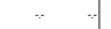 & & & & & 203.1 & 25.1 & $\because$ & 12.3 & & 123 & $\%$ & $\%$ & & & & & 37.4 \\
\hline 1978 & 2920 & $\because$ & 472 & $\ldots$ & 472 & $\approx$ & $\approx$ & & & $\because$ & $\cdots$ & 3992 & 45.7 & $\approx$ & 7.3 & & 7.3 & $\because$ & $\approx$ & & 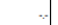 & & & 530 \\
\hline 1979 & 440.0 & $\because$ & 69.1 & & 69.1 & 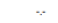 & $y$ & & & &. & 509.1 & 81.8 & $\because$ & 12.7 & & 127 & $\%$ & $\because$ & & & & & 94.5 \\
\hline 1980 & 594.4 & $\because$ & 528 & & 52.8 & $\cdots$ & $\approx$ & & & $\because$ & & 647.2 & 130.7 & $\approx$ & 11.5 & & 11.5 & $\%$ & $\approx$ & & 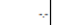 & & & 1422 \\
\hline 1981 & 2986 & $\approx$ & 70.6 & & $706 \mid$ & $\ldots$ & $y$ & & & $\because$ & & 3592 & 792 & $\approx$ & 188 & & 188 & $\approx$ & $\approx$ & & & & & 9800 \\
\hline 1982 & 1573 & $\%$ & 45.4 & & 45.4 & 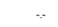 & $\because$ & & & & & 2027 & 42.3 & $\because$ & 12.2 & & 122 & $\because$ & $\because$ & & & & & 54.5 \\
\hline 1993 & 108.1 & $\approx$ & 51.9 & & 51.9 & $\approx$ & 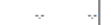 & & & & $\therefore$ & 160.0 | & 25.9 & $\approx$ & 12.5 & & 12.5 & $\approx$ & $\because$ & & 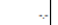 & & & 38.4 \\
\hline 1994 & 1123 & $\because$ & 95.1 & & 95.1 & $\%$ & $\because$ & & & & & 207.4 & \begin{tabular}{l|l}
25.6 &
\end{tabular} & $\approx$ & 22.1 & & 221 & $\%$ & $\because$ & & & & & 477? \\
\hline 1985 & 167.9 & $\approx$ & 118.8 & & 118.8 & $\because$ & 0.3 & 0.3 & & $\because$ & $\ldots$ & 287.0 & 29.0 & 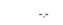 & 20.6 & & 20.6 & $\%$ & 0.1 & 0.1 & & & & 49.7] \\
\hline 1986 & 8328 & $\approx$ & 343.7 & & 343.7 & $*$ & $\%$ & $\therefore$ & & & $\cdots$ & $1,176.5$ & 186.4 & $\approx$ & 73.7 & & 73.7 & $\approx$ &. & & & & & 260.1 \\
\hline 1987 & 730.5 & $\because$ & 174.4 & & 174.4 &. & $\%$ & & & & & 9049 & 146.1 & $\because$ & 33.4 & & 33.4 & $\because$ & $\%$ & $\because$ & & & & \\
\hline 1998 & 822 & 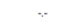 & 40.5 & & 40.5 & 29.3 & 0.6 & 299 & & & & 1526 & 12.6 & $\approx$ & 5.7 & & 5.7 & 5.6 & 0.1 & 5.7 & & & & 4.0 \\
\hline 1989 & 83.3 & $\approx$ & 469.8 & & 469.8 & 36.2 & 46.0 & 842 & & & & 637.3 & 36.2 & $\approx$ & 200.3 & & 200.3 & 15.1 & 16.0 & 31.1 & & & & 297.6 \\
\hline 1990 & 103.1 & $\%$ & 910.6 & & 910.6 & 31.2 & 23 & 33.5 & & 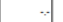 & 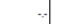 & 1,0472 & 69.2 & $\because$ & 559.4 & $\because$ & 553.4 & 21.2 & 1.4 & \begin{tabular}{l|l}
22.6 &
\end{tabular} & $\ldots$ & & & 6452 \\
\hline 1991 & 127.1 & $\%$ & 396.4 & & 396.4 & 872 & 13 & 88.5 & & & 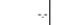 & 6120 & 122.7 & $\approx$ & 393.6 & & 333.6 & 84.5 & 1.2 & 85.7] & & & & 5920 \\
\hline 1992 & 3899 | & $\because$ & 168.1 & 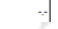 & 168.1 & 134.0 & 1.5 & 135.5 & & & & 693.5 & 408.8 & $\because$ & 178.8 & & 178.8 & 14.7 & 1.8 & 146.5 & & & & 734.1 \\
\hline 1993 & 1,6628 & $\approx$ & 7.3 & & 77.3 & 2828 & $\%$ & 282.8 & & & & $2,022.9$ & 1.629 .3 & $\approx$ & 75.5 & & 75.5 & 276.8 & $\because$ & 276.8 & & & & $1,981.6$ \\
\hline 1994 & 2.818 .1 & 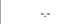 & & & 330.3 & 564.6 & $\%$ & \begin{tabular}{l|l}
564.6 \\
\end{tabular} & & & & 3.7113 .0 & $3,071.0$ & $\approx$ & 3627 & & 3627 & 620.9 & $\%$ & 620.9 & & & & $4,054,6$ \\
\hline 1995 & 3,2956 & $\because$ & $\quad 4392$ & & 4392 & 697.9 & $\%$ & 697 & & & & 4,4327] & $3,9260$. & $\because$ & 525.4 & & 525.4 & 8283 & $\because$ & 828.3 & & & & 5,279 \\
\hline 1996 & $3,164,3$ & $\approx$ & $\quad 2,8575$ & & $2,857.5$ & 957.2 & 21.3 & 978.5 & & & & $7,0000.3$ & 3,8402 & 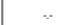 & 3,4648 & & $\begin{array}{l}3,4648 \\
\end{array}$ & $1,160.6$ & 25.5 & $1,186.1$ & & & & 8,491 . \\
\hline 1997 & $3,543.5$ & $\approx$ & $48,840.6$ & & $4,840.6$ & 1.454 .9 & 157.0 & 1.611 .9 & & & & $9,996.0$ & 4.2954 & $\because$ & $5,866.5$ & & 5.866 .5 & $1,70.2$ & 191.6 & 1961.8 & & & & $12,123.7$ \\
\hline 1998 & 2,596 & $*$ & $\quad 2,998.9$ & & $2,998.9$ & 826.3 & 88.6 & 914.9 & & & & & $3,000.9$ & $*$ & $3,559.3$ & & 3.5599 .3 & 999.6 & 106.4 & $1,096.0$ & & & & 7,7362 \\
\hline 1999 & 2,5962 & 134.5 & $\quad 1,173.7$ & 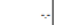 & $1,308.2$ & 407.0 & 117.3 & 524.3 & &. & & $4,428.7$ & $2,746.9$ & 141.5 & 12513 & $\because$ & 1,3928 & 430.8 & 124.0 & 554.8 & & & & $4,694.5$ \\
\hline 2000 & $2,371.13$ & 137.3 & 233.4 & 316.4 & 687.0 & 253.4 & 680 & 321.4 & & & & $3,379.8$ & 2.5212 & 144.9 & 249.0 & $3392]$ & 733.1 & 269.6 & 72.5 & 342.1 & & & & $3,596,4$ \\
\hline 2001 & 8640 & $\approx$ & 415.7 & 1,178.3 & $1,5940$. & 203.4 & 1018 & 3052 & & 355.8 & 10.4 & $3,3,59.4$ & 936.9 & $\ldots$ & 451.6 & $\begin{array}{r}1,2832 \\
\end{array}$ & $1,734.8$ & 220.1 & 109.3 & 329.4 & & 421.0 & 11.3 & $3,433.4$ \\
\hline 2002 & $1,095.1$ & $\ldots$ & 476.7 & 846.8 & 1.3235 & 194.6 & 51 & 1996 & 0.1 & 24.0 & 0.9 & $2,643.2$ & 1.18877 & $\because$ & 517.4 & $\begin{array}{r}9193 \\
\end{array}$ & $1,436.7$ & 215.8 & 5.5 & 221.3 & 0.1 & 25.9 & & $2,873.7$ \\
\hline 2003 & 823.3 & 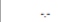 & 4479 & 540.5 & 968.4 & 1952 & 60 & 201.2 & & & 0.9 & $2,013.7$ & 921.8 & $\approx$ & 5026 & 6039. & $1,106.5$ & 218.6 & 6.7 & 225.2 & & & 1.0 & 2.2545 \\
\hline 2004 & $1,027.4$ & 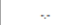 & 5039 & 257.9 & 761.8 & 291.5 & 67 & 298.2 & & & 0.1 & 2007.5 & 1244.8 & $\because$ & 592.3 & 3056 & 897.9 & 346.0 & 7.9 & 354.0 & & & 0.2 & $2,466.9$ \\
\hline 2005 & 1,7259 & $\approx$ & 6233 & 1659 & 789.2 & 406.9 & 0.4 & 415 & & & & $2,930.3$ & $2,1277]$ & $\approx$ & 776.1 & 207.0 & 983.1 & 506.4 & 9.9 & 516.8 & & & & $3,627.6$ \\
\hline 2006 & 3,633 & $\because$ & 468.1 & 1362 & 604.3 & 6513 & 43.8 & 695.1 & & & & 4,9330 & $4,677.3$ & $\because$ & 595.5 & 174.5 & 70.0 & 8359 & 55.5 & 891.4 & & & & 6.308 .7 \\
\hline 2007 & 6,84 & $*$ & 629.0 & 191.6 & 820.6 & $1,435.9$ & 18.5 & $1,454,4$ & & 25.2 & & $9,433.4$ & 9,287.7] & 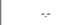 & 843.0 & 257.4 & $1,100.4$ & 1.952 .9 & 24.9 & $1,977.8$ & & 35.7 & & 12:401.7] \\
\hline 2008 & $3,304.8$ & $\approx$ & 920.1 & 26.8 & 946.9 & 841.7 & 125 & 854.2 & & 5.6 & & $5,111.5$ & $5,10.8$ & $\because$ & $1,404.0$ & 40.8 & 1,444.7. & $1,304.1$ & 192 & 1.323.3. & & 89 & & $7,887.7$ \\
\hline 2008 & 2.56 & $\%$ & 485.0 & 1998 & 684.8 & 396.6 & 62 & 405 & & 5.5 & & 3.656 .4 & 4.007.1 & $\approx$ & 749.0 & 314.5 & 1.0635 & 617.7 & 9.3 & 631.2 & & & & \\
\hline 201 & $3,001.9$ & $\approx$ & 266.5 & 1186 & 385.1 & 577.6 & 4.1 & 581 & & 66.1 & & $4,034.7$ & 5,0278 & $\cdots$ & 443.7 & 197.0 & 640.7 & 961.7 & 6.8 & 968.5 & & 111.6 & & \\
\hline 2011 & 3,55 & $\because$ & 308.7 & 553 & 363.9 & 519.6 & 37 & 523 & & 7.6 & & 4,449 & 6.241 .8 & $\because$ & 5450 & 96.7 & 641.7 & 913.4 & 6.6 & 920.0 & & 13.6 & & \\
\hline 2012 & 3,15 & $*$ & 253.4 & 16.4 & 2698 & 484.6 & 53 & 489.9 & & 29.8 & & 3.9492 & 6,1085 & $\approx$ & 483.6 & 31.8 & 515.4 & 927.0 & 10.1 & 937.2 & & \begin{tabular}{l|l}
55.5 \\
\end{tabular} & & 7,611 \\
\hline 2013 & $2,123.9$ & $\because$ & 414.1 & 422 & 456.3 & 486.3 & 62 & 4926 & & 41.0 & & $3,113.8$ & 4,0005 & $\approx$ & 7929 & 79.7 & 8726 & 937.0 & 11.9 & 949.0 & & 80.4 & & 6,0023 \\
\hline 201 & 2,04 & $*$ & 374.3 & 1823 & 556.6 & 450.1 & 152 & 465 & & $\begin{array}{l}5.8 \\
\end{array}$ & & 3.068 & 3.847.7. & $\%$ & 707.7 & 343.6 & 1.051 .3 & 849.4 & 28.8 & 878.2 & & 11.0 & & \\
\hline 2015 & $1,006.3$ & $\approx$ & 3123 & 275.6 & 5879 & 3120 & 14.1 & 326.1 & & 13.7] & & $2,014.0$ & 1.8995 & $\therefore$ & 545.1 & 478.4 & $1,023.5$ & 545.0 & 24.5 & 569.5 & & 23.7 & & $3,516.2$ \\
\hline 2016 & $1,561.7$ & $\cdots$ & 183.0 & 628.5 & 811.5 & 258.1 & 342 & 292.3 & & 12.7 & & 2.678 .3 & 2.665 .5 & $\approx$ & 308.6 & 1.0720 & 1.380.6 & 440.1 & 58.0 & 498.3 & & 21.7 & & 4.566 .1 \\
\hline 2017 & $3,496,4$ & $\approx$ & 184.4 & 874.0 & 1.058 .4 & 3669 & 18.4 & 365.4 & & 21.0 & & $4,961.1$ & 6,2927 & $\approx$ & 3339 & $\begin{array}{l}1,580.9 \\
\end{array}$ & 1.914 .8 & 6646 & 33.3 & 698.1 & & 38.1 & & $8,943.7$ \\
\hline
\end{tabular}

